\title{
JNK pathway mediates apoptotic cell death induced by tumor suppressor LKB1 in Drosophila
}

\author{
JH Lee ${ }^{1}$, H Koh ${ }^{1}$, M Kim¹, J Park', SY Lee ${ }^{1}$, S Lee ${ }^{1}$ and \\ J Chung ${ }^{\star, 1}$ \\ 1 National Creative Research Initiatives Center for Cell Growth Regulation and \\ Department of Biological Sciences, Korea Advanced Institute of Science and \\ Technology, 373-1 Kusong-dong, Yusong, Taejon, Korea \\ * Corresponding author: J Chung, Department of Biological Sciences, Korea \\ Advanced Institute of Science and Technology, 373-1 Kusong-dong, Yusong, \\ Taejon 305-701, Korea. Tel: + 8242869 2620; Fax: + 8242869 8260; \\ E-mail: jchung@kaist.ac.kr
}

Received 13.6.05; revised 25.8.05; accepted 08.9.05; published online 04.11.05 Edited by M Miura

\begin{abstract}
Although recent progresses have unveiled the diverse in vivo functions of LKB1, detailed molecular mechanisms governing these processes still remain enigmatic. Here, we showed that Drosophila LKB1 negatively regulates organ growth by caspase-dependent apoptosis, without affecting cell size and cell cycle progression. Through genetic screening for LKB1 modifiers, we discovered the JNK pathway as a novel component of LKB1 signaling; the JNK pathway was activated by LKB1 and mediated the LKB1-dependent apoptosis. Consistently, LKB1-null mutant was defective in embryonic apoptosis and displayed a drastic hyperplasia in the central nervous system; these phenotypes were fully rescued by ectopic JNK activation as well as wild-type LKB1 expression. Furthermore, inhibition of LKB1 resulted in epithelial morphogenesis failure, which was associated with a decrease in JNK activity. Collectively, our studies unprecedentedly elucidate JNK as the downstream mediator of the LKB1dependent apoptosis, and provide a new paradigm for understanding the diverse LKB1 functions in vivo.

Cell Death and Differentiation (2006) 13, 1110-1122.

doi:10.1038/sj.cdd.4401790; published online 4 November 2005
\end{abstract}

Keywords: apoptosis; cell cycle; caspase; brain hyperplasia

Abbreviations: JNK, c-Jun N-terminal kinase; PJS, PeutzJegher syndrome; TSC, tuberous sclerosis complex

\section{Introduction}

Tumor suppressor LKB1 is a serine/threonine kinase that is heterozygotically mutated in the germ line of Peutz-Jegher syndrome (PJS) patients. ${ }^{1,2}$ PJS patients have a highly increased risk of malignant tumors, especially in the gastrointestinal tract, breast, uterine cervix, and ovary. ${ }^{3-5}$ Many of these tumors acquire somatic mutations in the remaining wildtype allele of $\angle K B 1{ }^{6,7}$ Moreover, various sporadic cancers are also associated with the loss of LKB1, implicating the general role of LKB1 in tumor suppression. ${ }^{8-10}$ As point mutations of LKB1 found in PJS mostly reside in the highly conserved kinase domain, it is very likely that the kinase activity of LKB1 is essential for its tumor suppressive function. ${ }^{11,12}$

Since the discovery of LKB1 in 1998, various functions of LKB1 molecule were suggested to be responsible for its tumor-suppressing activity - such as inhibition of cell cycle progression, cell growth retardation, apoptotic cell death, and cell polarity control. ${ }^{11,13}$ The LKB1 protein was originally characterized as a cell cycle inhibitor, and its putative downstream targets such as Brg1 and p21 were suggested to mediate LKB1-dependent cell cycle arrest. ${ }^{14-16}$ It has been recently proposed that LKB1 also regulates cellular growth by controlling another tumor suppressor tuberous sclerosis complex (TSC) via the AMP kinase (AMPK)-dependent pathway. ${ }^{17,18}$ In addition, studies showing the absence of apoptosis in PJS polyps revealed that LKB1 is an inducer of apoptosis in vivo. ${ }^{19}$ Another tumor suppressor $\mathrm{p53}$, the first identified in vitro substrate of LKB1, was proposed as a mediator of this apoptosis. ${ }^{19,20}$ Finally, LKB1 was shown to be necessary for the polarization of intestinal epithelial cells and Drosophila ovary cells, demonstrating another important function of LKB1 in regulating cell structure..$^{21,22}$

Although considerable progress has been made to characterize the in vivo function of LKB1, only a limited amount of information concerning its molecular mechanisms has been found in detail; the major biological pathway responsible for the tumor suppressive function of LKB1 remains to be clarified.

The c-Jun N-terminal kinase (JNK) is a member of the mitogen-activated protein kinase (MAPK) family that mediates various cellular responses including programmed cell death, epithelial sheet movement, and planar polarity. ${ }^{23}$ The activity of JNK is tightly regulated by reversible phosphorylation, which is stimulated by a sequential cascade of protein kinases and inhibited by JNK-specific phosphatases. Activation of the JNK pathway is required for the release of cytochrome $c$ from the mitochondria and the subsequent activation of the caspase cascade. ${ }^{24}$ Therefore, abrogation of the JNK signaling pathway causes various defects in developmental or stressinduced apoptosis. ${ }^{25,26} \mathrm{In}$ addition to controlling apoptosis, regulation of epithelial morphogenesis is another well-known function of the JNK signaling pathway. ${ }^{27}$ Depletion of JNK activity results in various epithelial defects, including those of dorsal closure and planar polarity in Drosophila, and of the optic and neuronal system in mice. ${ }^{28-32}$

Since JNK is required for apoptosis and epithelial organization, disruption of the JNK signaling pathway is thought to be a prerequisite of tumorigenesis by enabling tumor cells to evade programmed cell death and to acquire a metastatic potential. $^{33}$ Indeed, JNK1 and JNK2 are both required for the suppression of oncogenic transformation and tumorigenesis. ${ }^{34}$ Loss of JNK3, which is selectively expressed in neuronal cells, is also closely associated with human brain tumors. ${ }^{35}$ Furthermore, the Mkk4 gene, which encodes an 
upstream kinase of JNK, has been identified as a tumor suppressor gene and a metastasis suppressor gene. ${ }^{36,37}$

In this paper, we are the first to show a genetic connection between tumor suppressor LKB1 and the JNK signaling pathway. Our results indicate that LKB1 activates the JNK pathway in vivo and that the JNK pathway mediates the LKB1dependent apoptotic cell death.

\section{Results}

\section{LKB1 negatively regulates compartment size}

Using various Gal4 drivers, we were able to achieve a highlevel expression of both wild-type and kinase-dead LKB1 in the specific region of various tissues: the posterior region of the eye imaginal disc by the glass_multiple_reporter-Gal4 driver (gmr-Gal4; Figure 1a,b), the dorsal region of the wing disc by the apterous-Gal4 driver (ap-Gal4; Figure 1c, d), and the central pouch region of the wing disc by the ms1096-Gal4 driver (Figure 1e,f). The expression levels of the LKB1 protein were determined by immunostaining using Drosophila LKB1specific antisera. Eye-specific expression of wild-type LKB1 by the gmr-Gal4 driver induced a slight reduction in overall eye size (Figure 1g, h), and this reduction became severer when the LKB1 expression level was elevated (Figure 1j). However, the kinase-dead LKB1 overexpression did not induce this specific phenotype (Figure 1i), showing that the kinase activity of LKB1 is important in inducing tissue-size reduction. The dorsal region-specific expression of wild-type and kinasedead LKB1 by the ap-Gal4 driver displayed more dramatic phenotypes. As Drosophila wing discs are composed of two layers of tissues, dorsal and ventral, alterations in size of only the dorsal layer give rise to bent-up or bent-down wing phenotypes. ${ }^{38}$ Although the dorsal tissue-specific expression of kinase-dead LKB1 did not induce any alterations (Figure $1 \mathrm{k}, \mathrm{m})$, wild-type LKB1 induced a dramatic bent-up wing phenotype (Figure 1I, n) in a dose-dependent manner. Consistently, the ms1096-Gal4-driven expression of wildtype LKB1 dose-dependently reduced the overall wing size (Figure 10, p, r), although kinase-dead LKB1 did not (Figure 1q). Therefore, we concluded that Drosophila LKB1 negatively regulates the tissue and organ size in a kinase activity-dependent manner.

\section{LKB1 reduces clone size but not cell size}

To examine the effect of LKB1 in individual cells, we performed clonal analyses by inducing LKB1 overexpression
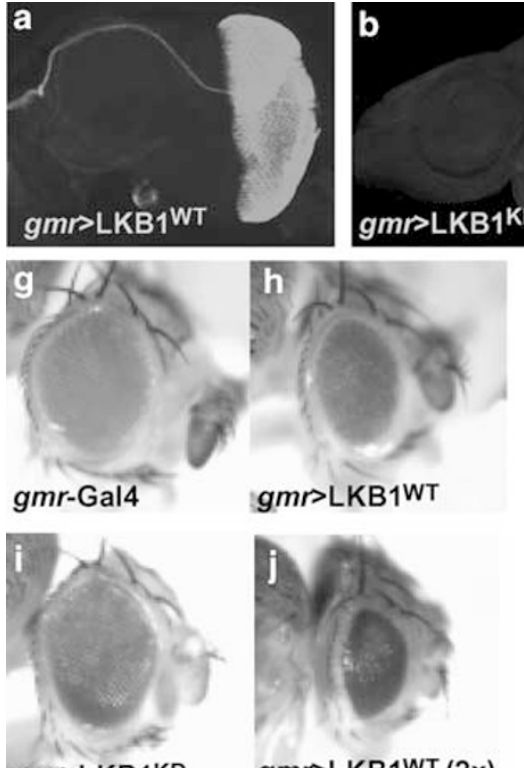

$g m r$ LKB1KD gmr $>$ LB1WT

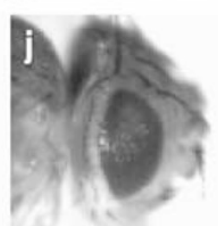

$g m r>L K B 1 W T(2 x)$

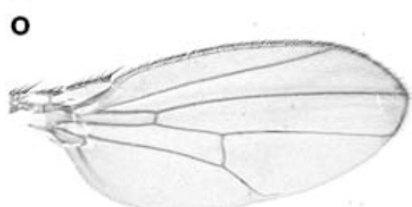

ms1096-Gal4

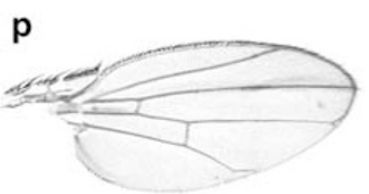

$m s 1096>$ LKB1WT

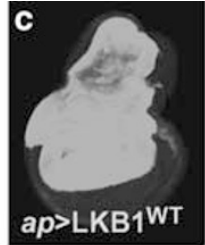

k

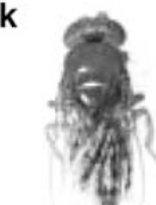

$a p>G F P$

$\mathrm{m}$
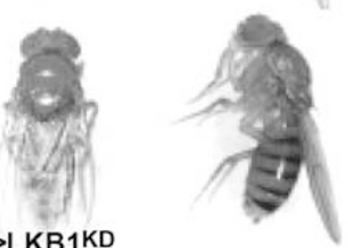
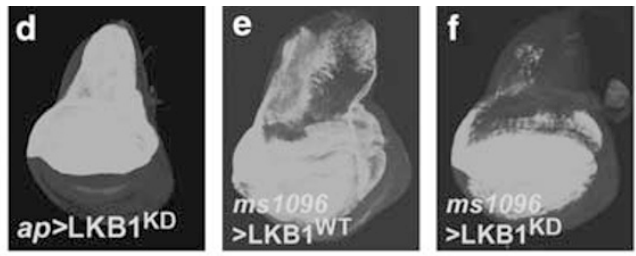

I
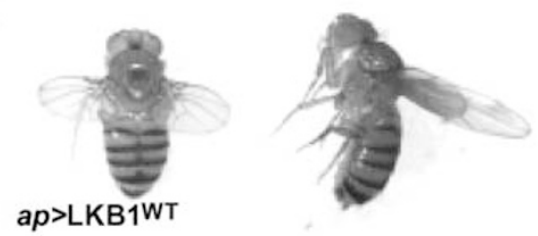

n

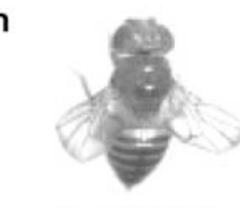

$a p>2 x L K B 1 W T$

q

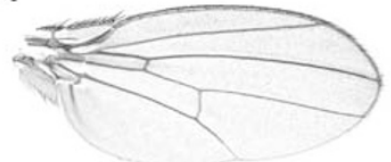

$m s 1096>$ LKB1KD r
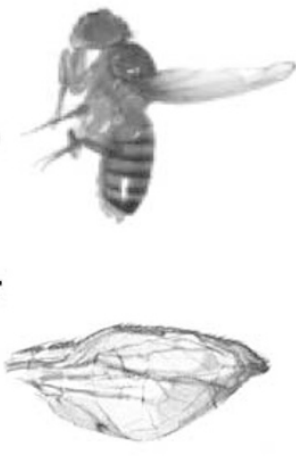

ms1096>LKB1WT (2x)

Figure 1 LKB1 reduces organ size in a kinase activity-dependent manner. (a-f) Tissue-specific expression of Drosophila LKB1. gmr-Gal4- (a, b), ap-Gal4- (c, d), or ms 1096-Gal4- (e, f) driven expression of wild-type LKB1 (LKB1 $\left.{ }^{\text {WT }}\right)(\mathbf{a}, \mathbf{c}, \mathbf{e})$ and kinase-dead LKB1 (LKB1 ${ }^{K D}$ ) (b, d, f) was visualized using anti-LKB1 antisera. No specific signals were observed in wild-type imaginal discs (data not shown). (g-j) Adult fly eyes expressing LKB1 transgenes under the control of gmr-Gal4. Genotypes are: gmr$\mathrm{Gal} 4 /+(\mathbf{g}), g_{m r-G a l 4 / U A S-L K B 1}{ }^{\mathrm{WT}}$ (h), gmr-Gal4/UAS-LKB1 ${ }^{\mathrm{KD}}$ (i), and gmr-Gal4 UAS-LKB1 ${ }^{\mathrm{WT}} /$ gmr-Gal4 UAS-LKB1 $^{\mathrm{WT}}$ (j). (k-n) Dorsal (left) and lateral (right) views of flies expressing transgenes under the control of ap-Gal4. Genotypes are: ap-Gal4/UAS-GFP (k), ap-Gal4/UAS-LKB1 ${ }^{\text {WT }}$ (I), ap-Gal4/UAS-LKB1 ${ }^{\text {KD }}$ (m), and ap-Gal4 UAS-LKB1 ${ }^{\text {WT} / U A S-L K B 1 ~}{ }^{\text {WT }}$ (n). (o-r) Adult fly wings expressing transgenes under the control of ms1096-Gal4. Genotypes are: ms1096-Gal4/Y (o), ms1096-Gal4 UAS$\mathrm{LKB1}^{\mathrm{WT}} / \mathrm{Y}(\mathbf{p}), \mathrm{ms}_{1096-G a l 4 / Y}$; UAS-LKB1 ${ }^{\mathrm{KD}} /+(\mathbf{q})$, and $m s 1096-G a l 4$ UAS-LKB1 ${ }^{\mathrm{WT}} / m s 1096-G a l 4$ UAS-LKB1 $^{\mathrm{WT}}$ (r) 
in a specific subset of cells within wing imaginal discs. Compared to the control clones expressing only GFP (Figure $2 \mathrm{a}, \mathrm{d})$, the LKB1-expressing clones expanded very poorly (Figure 2b, e). Similarly, overexpression of the TSC complex, another well-known tumor suppressor, also decreased the clone size, although with a milder severity than the overexpression of LKB1 (Figure $2 \mathrm{c}, \mathrm{f}$ ). ${ }^{39}$

Recent mammalian studies suggested that LKB1 negatively regulates TOR signaling via the AMPK-TSC pathway. ${ }^{17,18}$ Since reduction in cell size is a typical outcome of TSC overexpression, we attempted to test whether the LKB1 overexpression phenotype results from cell size reduction. $^{39,40}$ As expected, the overexpression clones of TSC (Figure $2 \mathrm{i}$ ) displayed a dramatic reduction in wing marginal bristle size. However, surprisingly, although LKB1 reduced clone size more severely than did TSC, LKB1 expression did not cause any alterations in the bristle size (Figure $2 g, h$ ). Consistently, in contrast to TSC (Figure 2j, I), LKB1 again failed to reduce the bristle size when expressed by the ms 1096-Gal4 driver (Figure 2j, k). Furthermore, LKB1 overexpression in the clones of endoreplicating tissues, such as the salivary gland and fat body, altered neither the cell size nor the DNA content (data not shown), confirming that the tumorsuppressing activity of LKB1 is unrelated to the negative regulation of cell growth control. Therefore, we concluded there to be no connection between LKB1 and TSC in the context of cell growth regulation in Drosophila.

\section{LKB1 induces apoptotic cell death but not cell cycle arrest}

Since the LKB1-dependent reduction of tissue size appropriately reflected the tumor-suppressing activity of LKB1, we assessed whether this tissue-size reduction is caused by cell cycle arrest or apoptotic cell death, both of which have been proposed as major cellular processes underlying the tumorsuppressing function of LKB1. ${ }^{11}$ To check the G1-S cell cycle progression of LKB1-expressing tissues, we performed the bromodeoxyuridine (BrdU) incorporation assay, which specifically labels S-phase cells. Although LKB1 was highly expressed in these tissues (Figure 1), no significant alterations in the S-phase cell number were detected (Figure $3 b, d$ and e) with respect to the control tissues (Figure $3 a, c$ ). Similarly, there was no change in the antiphosphospecific histone 3 (PH3) antibody staining pattern between the wildtype (Figure $3 f$ and $h$ ) and the LKB1-expressing tissues (Figure $3 \mathrm{~g}, \mathrm{i}$ and $\mathrm{j}$ ), demonstrating that G2-M cell cycle transition was also unaffected. However, when the equivalent
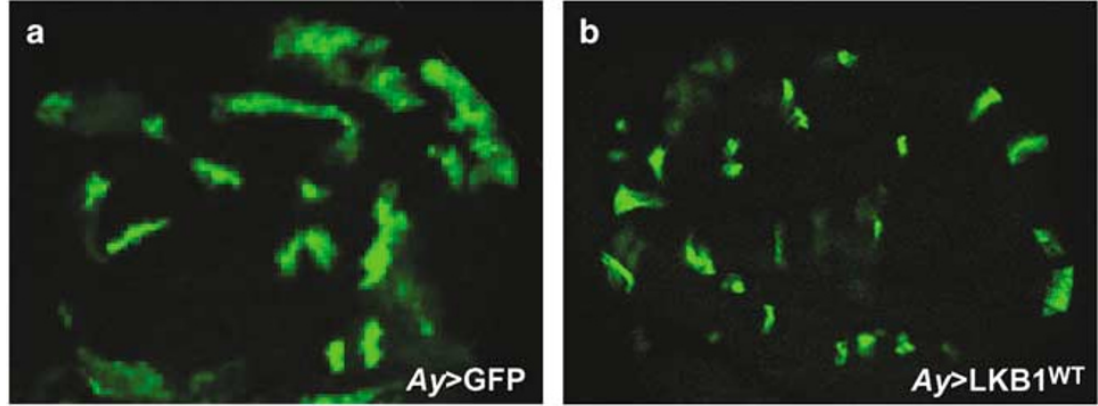

d
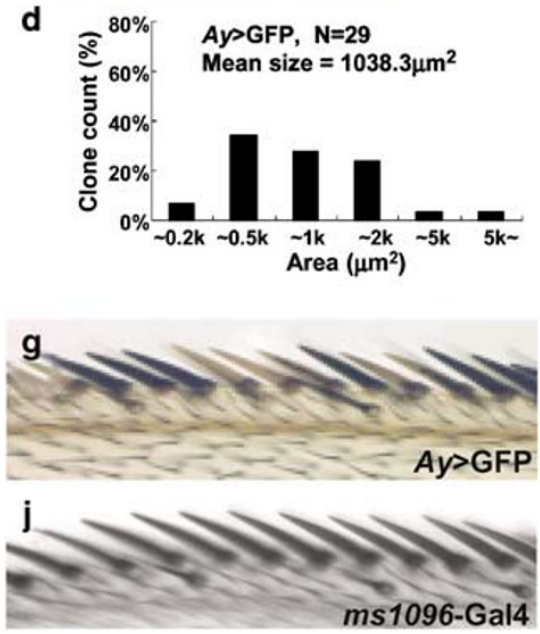

e
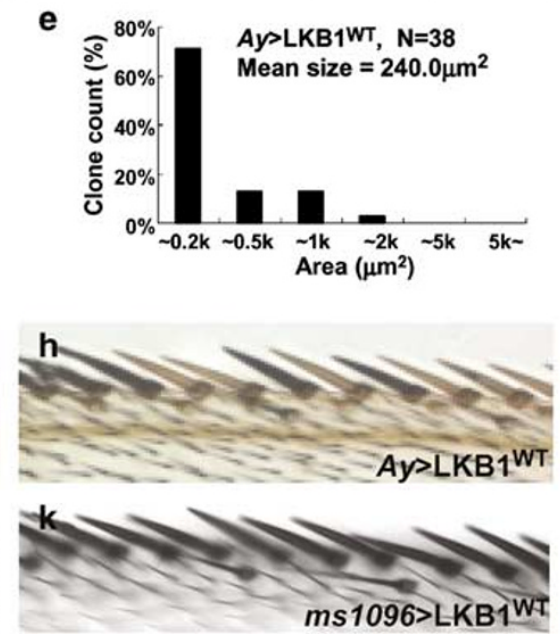

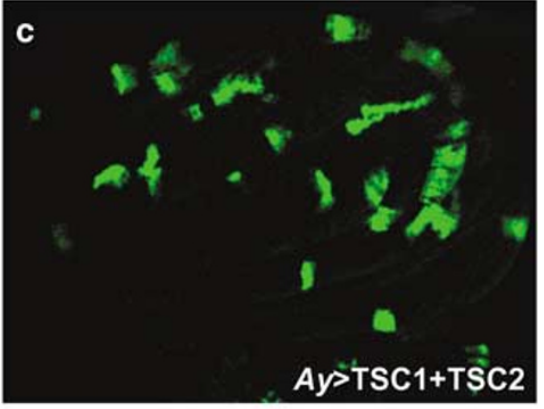

$f \quad$ Ay>TSC1+TSC2, $\mathrm{N}=46$
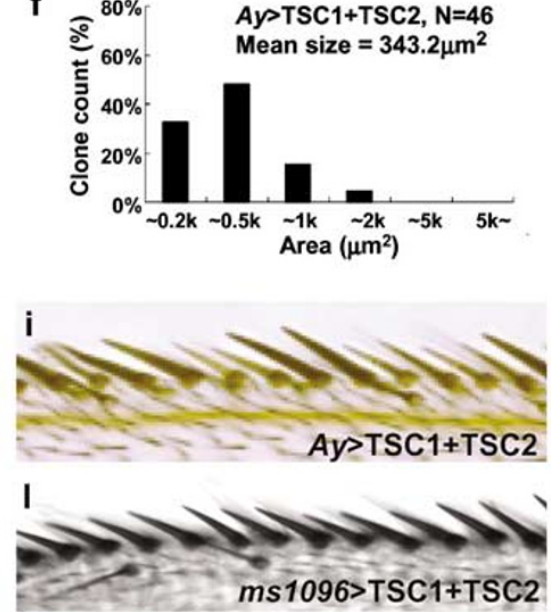

Figure 2 LKB1 reduces clone size without affecting cell size. (a-c) Flipped-out clones expressing either GFP alone (a); GFP and LKB1 (b); and GFP, TSC1, and TSC2 (c) were photographed $70 \mathrm{~h}$ after clone induction. (d-f) Distributions of clonal areas $\left(k=1000 \mu \mathrm{m}^{2}\right)$ in flipped-out clones expressing GFP alone (d); GFP and LKB1 (e); and GFP, TSC1, and TSC2 (f) were presented as bar graphs. Numbers of clones examined and means of clone sizes are indicated in the graphs. (g-i) Wing marginal bristle sizes were examined in yellow-negative clones expressing GFP alone (g); GFP and LKB1 (h); and GFP, TSC1, and TSC2 (i). (j-l) Wing marginal bristles expressing transgenes under the control of ms1096-Gal4. Genotypes: $y$ whs-FLP/ +; Ay-Gal4 UAS-GFP/ + (a, d, g), y whs-FLP/ +; Ay-Gal4 UAS-GFP/UAS-LKB1 ${ }^{\mathrm{WT}}$ (b, e, h), y w hs-FLPI + ; Ay-Gal4 UAS-GFP/UAS-TSC1 UAS-TSC2 (c, f, i), ms1096-Gal4/Y (j), ms1096-Gal4 UAS-LKB1 ${ }^{\mathrm{WT}} / \mathrm{Y}$ (k), and ms1096-Gal4/Y; UAS-TSC1 UAS-TSC2/ + (I) 

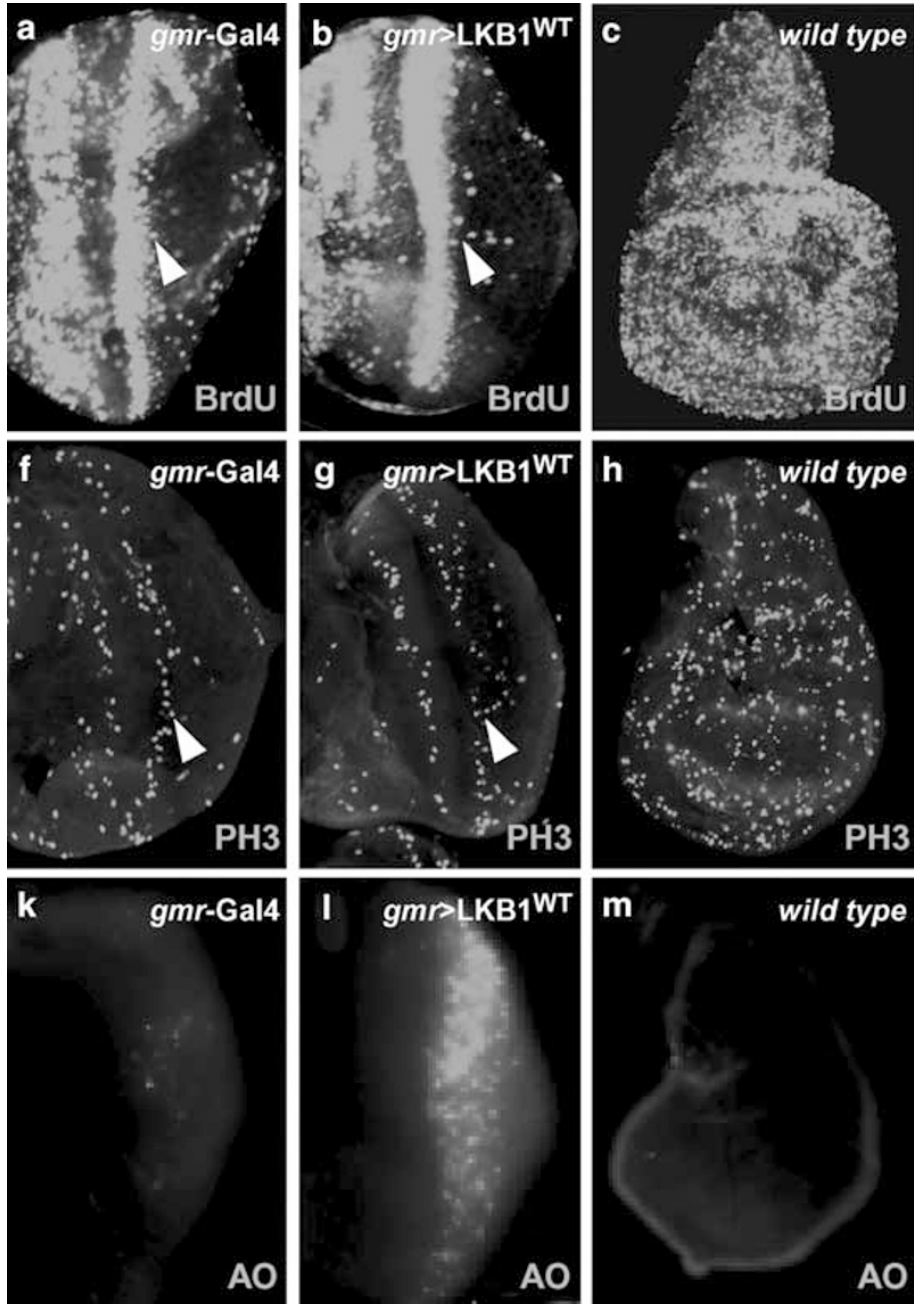
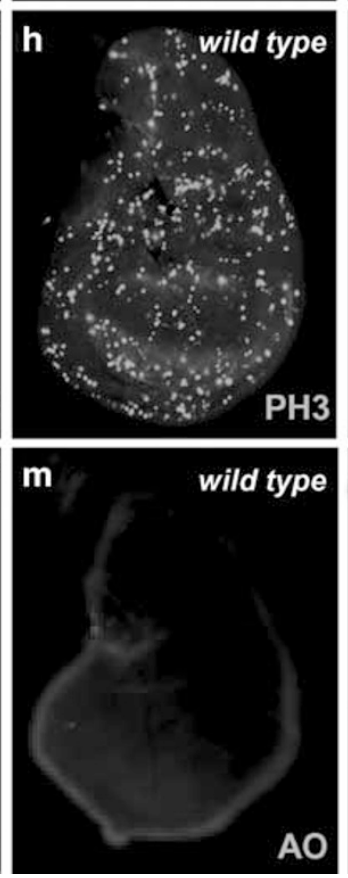
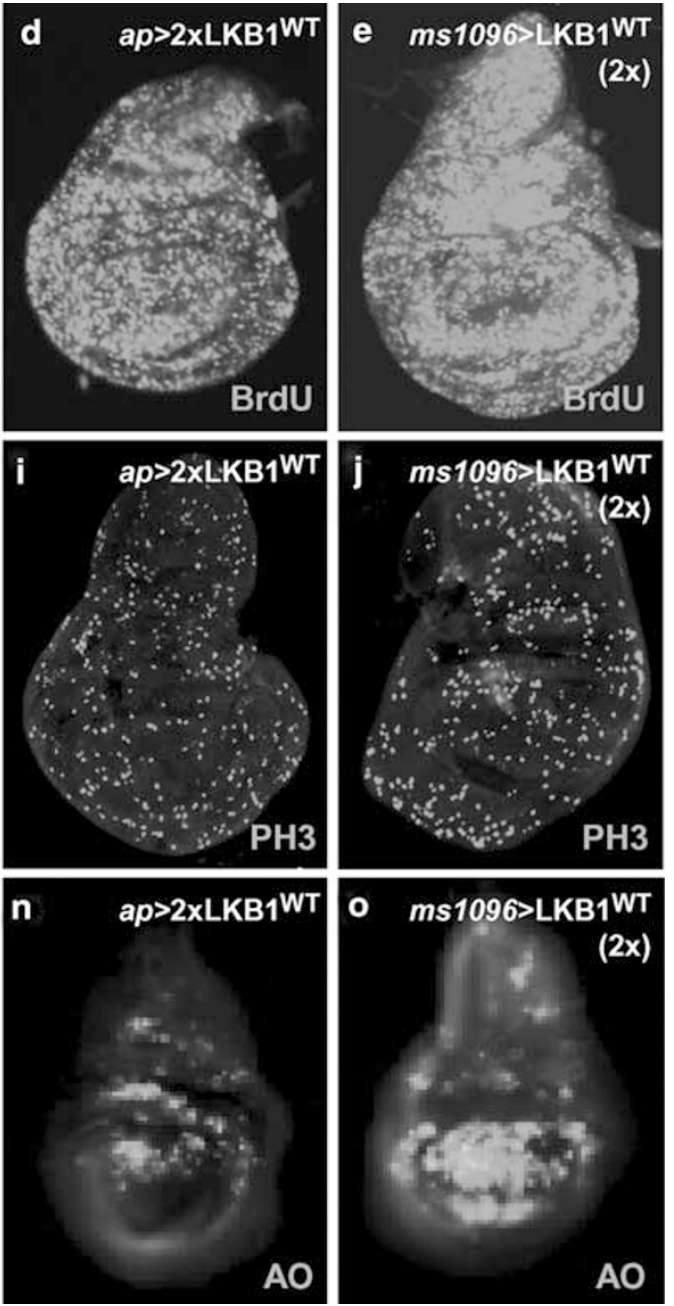

Figure 3 LKB1 promotes cell death without affecting cell cycle progression. (a-e) Eye discs (a, b) and wing discs (c-e) of indicated genotypes were analyzed by BrdU staining. Spots indicate S-phase cells with DNA replication. A white arrowhead indicates the normal position of the second mitotic wave. (f-j) Eye discs (f, $\mathbf{g})$ and wing $\operatorname{discs}(\mathbf{h}-\mathbf{j})$ of indicated genotypes were analyzed by antiphosphospecific histone 3 (PH3) antibody staining. Spots indicate mitotic cells with condensed chromosomes. A white arrowhead indicates the normal position of the second mitotic wave. $(\mathbf{k}-\mathbf{0})$ Eye discs $(\mathbf{k}, \mathbf{I})$ and wing discs $(\mathbf{m}-\mathbf{0})$ of indicated genotypes were analyzed by acridine orange (AO) staining. Spots indicate apoptotic cells with disrupted membrane integrity. The regions of extensive apoptotic signals (l, $\mathrm{n}, \mathbf{0})$ largely overlap with the regions of LKB1 expression (Figure 1a, c and $\mathbf{e}$ )

tissues were subjected to acridine orange (AO) staining, which specifically labels the dying cells with disrupted membrane integrity, they displayed prominent death signals (Figure $3 \mathrm{l}, \mathrm{n}$ and o) compared to the controls (Figure $3 \mathrm{k}, \mathrm{m}$ ), specifically in the region of LKB1 overexpression (Figure 1a, $\mathrm{C}$ and e). These results strongly implied that the LKB1-induced organ size reduction is caused by apoptotic cell death, not by cell cycle arrest. Furthermore, TUNEL staining of the eye (Figure 4a, b) and wing discs (data not shown) also confirmed the existence of extensive apoptosis in the LKB1-expressing cells. Therefore, we concluded LKB1 to be a potent apoptosis instigator in Drosophila.

\section{LKB1-induced apoptosis is caspase dependent but p53 independent}

It has been reported that mammalian LKB1 physically associates with p53, and that Drosophila p53 is involved in the cell death process. ${ }^{19,41-43}$ Therefore, we questioned whether LKB1-dependent apoptosis requires p53 activity. When a dominant-negative p53 was expressed by the gmrGal4 driver, the ionizing radiation-dependent apoptosis which is fully dependent on p53 - was specifically suppressed in the gmr-expressing region (Figure 4c,d), demonstrating that the dominant-negative p53 is sufficient to inhibit endogenous p53 activity. However, the LKB1-induced apoptosis (Figure 3I) was not suppressed at all by the dominantnegative p53 (Figure 4e), while Drosophila inhibitor of apoptosis (DIAP) completely suppressed the LKB1-induced apoptosis (Figure 4f). Interestingly, even when the LKB1induced apoptosis was completely blocked by DIAP, the BrdU (Figure 4h) and $\mathrm{PH} 3$ (Figure 4i) staining patterns were not significantly deviated from the wild-type patterns (Figure $3 a, f)$, further confirming that LKB1 does not affect cell cycle progression. Since DIAP directly blocks caspase activity, we deduced the LKB1-induced apoptosis to be caspase depen- 

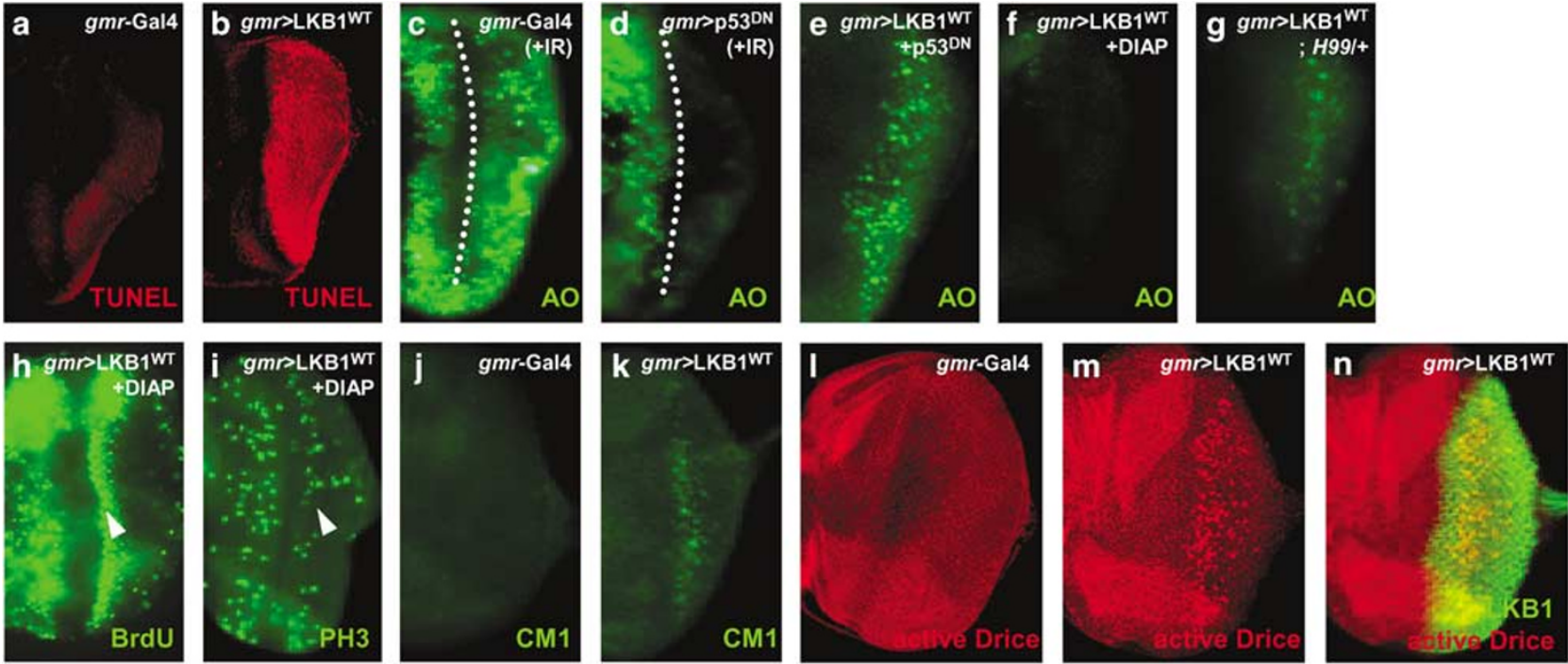

Figure 4 LKB1-induced apoptosis is caspase dependent but p53 independent. (a, b) Eye discs of indicated genotypes were analyzed by TUNEL staining. Red spots indicate DNA fragmentation in apoptotic cells. (c, d) Eye discs were analyzed by AO staining. Prior to dissection, third instar larvae were challenged by gamma-irradiation at 4000 rads $(+\mathrm{IR})$, and incubated $4 \mathrm{~h}$ at $25^{\circ} \mathrm{C}$. Note the absence of apoptosis after the morphogenetic furrow (dotted line) of $g m r-G a l 4 /+; \mathrm{UAS}-p 53^{\mathrm{DN}} /+$ eye discs (d), compared to the control gmr-Gal4/ + eye discs (c). (e, f, g) Eye discs from gmr-Gal4 UAS-LKB1 ${ }^{\mathrm{WT}} /+$ flies with either UAS-p53 ${ }^{\mathrm{DN}}$ (e), UAS-DIAP (f), or Df(3L)H99

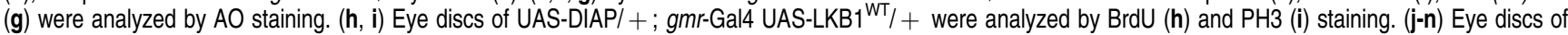
indicated genotypes were analyzed by immunostaining using antiactive caspase-3 (CM1; green spots in j and k), antiactive Drice (active Drice; red spots in I-n), and antiLKB1 (LKB1; green area in $\mathbf{n}$ ) antibodies

dent but p53 independent. ${ }^{44}$ Consistently, extensive caspase activation was observed in the LKB1-overexpressed region (Figure $4 \mathrm{n}$ ), detected by either CM1 antibody (Figure $4 \mathrm{j}, \mathrm{k}$ ) or antiactive Drice antibody (Figure 4I-n).

\section{Endogenous LKB1 is required for developmental apoptosis}

Next, we questioned whether endogenous LKB1 is required for developmental apoptosis and subsequent control of organ size in Drosophila. In order to address this, we generated an $L K B 1$-null mutant allele, $L K B 1^{X 5}$ with a specific deletion in the LKB1 locus (76208-77847th nucleotides of AE003701; Figure $5 a$ ), leading to the complete loss of $L K B 1$ transcripts (Figure $5 \mathrm{~b}$ ). Every $L K B 1^{X 5}$ mutant, as well as the previously described $L K B 1^{4 A 4-2}$ mutant, died before mid-pupal stage. ${ }^{22}$ Transgenic expression of wild-type LKB1 using the $h s-G a l 4$ driver successfully rescued the lethality of $L K B 1^{X 5}$ showing the authenticity of $L K B 1^{X 5}$-null allele (data not shown).

To substantiate whether the endogenous LKB1 is required for apoptosis, we performed TUNEL staining of wild-type and $L K B 1$-null embryos. As the nerve cord condensed (embryonic stage 16), prominent cell death was observed throughout the central nervous system of wild-type embryos (Figure 5c, e) ${ }^{45}$ However, in $L K B 1^{X 5}$ homozygous embryos, significantly fewer apoptotic cells were observed both in the ventral nerve cord (Figure 5d) and the embryonic head (Figure 5f) region, which was completely reversed by transgenic LKB1 ${ }^{\mathrm{WT}}$ expression (data not shown). Moreover, when stained with anti-Elav antibody, which recognizes all differentiated neurons, $L K B 1^{X 5}$ homozygous embryos showed a dramatically increased mass of Elav-positive cells in the brain (Figure $5 \mathrm{~h}$ ) compared to that in wild type (Figure $5 \mathrm{~g}$ ).
As some $L K B 1$-null animals escaped their embryonic lethality and further developed into pupal stages, we questioned whether LKB1-null mutant shows brain hyperplasia during larval stages as in the Apaf- 1 null mutants. ${ }^{46,47}$ Hence, we dissected the brain lobes and ventral ganglion from the wandering third instar larvae of wild-type and $L K B 1$-null mutants. Strikingly, in $L K B 1^{X 5}$ homozygous larvae, the brain hemispheres and ventral ganglion were dramatically enlarged (Figure 5j) compared to those in wild type (Figure 5i), and this phenotype was consistently observed in $L K B 1^{4 A 4-2}$ mutants (Figure 5k). Furthermore, ectopic expression of LKB1 ${ }^{\mathrm{WT}}$ successfully suppressed this big-brain phenotype (Figure 5I), confirming that the brain hyperplasia is indeed due to the absence of LKB1 activity. Therefore, we concluded that endogenous LKB1 regulates organ size of the central nervous system by inducing developmental apoptosis during embryogenesis.

\section{Grim, reaper, and hid are located downstream of LKB1}

Apoptotic defects and neuronal hyperplasia of LKB1-null mutants are strikingly similar to the phenotypes of other Drosophila mutants deficient in apoptosis-inducing genes, such as grim, reaper, and hid. ${ }^{48}$ Since the activation of these apoptosis instigators also induces extensive caspase activation, we speculated that these genes are involved in LKB1dependent apoptosis. Interestingly, we found that the dosage reduction of grim, reaper, and hid genes alleviates the LKB1induced apoptosis (Figure $4 \mathrm{~g}$ ). However, the dosage reduction of LKB1 did not affect apoptosis induced by reaperand hid (Supplementary Figure 2a,b), implicating that LKB1 exists upstream of these genes. 
a
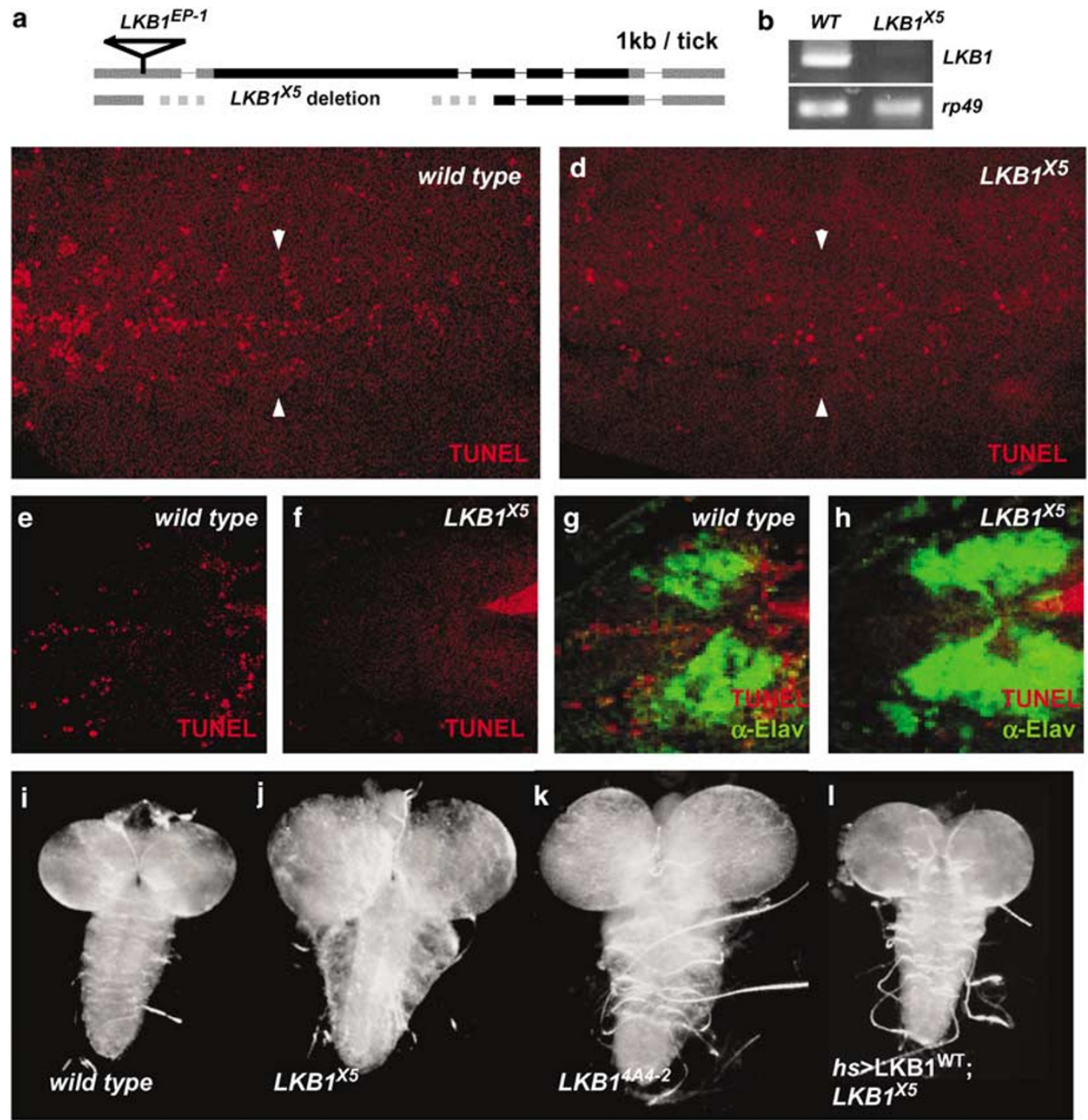

Figure 5 Endogenous LKB1 is required for embryonic neuronal apoptosis. (a) Genomic organization of $L K B 1$ locus. The P-element insertion site of original $L K B 11^{E P-1}$ allele (triangle) and the deletion site of the $L K B 1^{\times 5}$ allele were presented (dotted line). Thick line (gray: noncoding region, black: coding region) indicates exons of $L K B 1$ gene, and thin line indicates introns of $L K B 1$ gene. (b) Absence of $L K B 1$ message in $L K B 1^{X 5}$-null larvae. Extensive RT-PCR ( $\sim 40$ cycles) could not detect any $L K B 1$ signals from $L K B 1^{X 5}$ larvae, while a strong $L K B 1$ signal was detected in $w^{1118}$ larvae. rp49 was used as a loading control (bottom panel). (c-f) Reduced apoptosis in $L K B 1^{X 5}$ mutant. Embryos were stained with TUNEL (red spots) to detect relative levels of apoptosis. Ventral nerve cords (c, $\mathbf{d}$; between the arrowheads) and brains (e, $\mathrm{f}$ ) of comparably staged $w^{1118}(\mathbf{c}, \mathbf{e})$ and $L K B 1^{X 5}(\mathbf{d}, \mathbf{f})$ embryos (stage 16) were stained. $(\mathbf{g}, \mathbf{h})$ Embryos were simultaneously stained by anti-Elav antibody (green area) to visualize neurons of (e) and (f). Note the expansion of Elav-stained area (green in $\mathbf{h}$ ) onto the normally apoptosis-occurring region (red spots in $\mathbf{g}$ ). (i-l) CNS dissections from third instar larvae of indicated genotypes. Quantification of brain phenotypes is presented in Supplementary Figure 3 as a bar graph

\section{LKB1 is dispensable for p53-dependent apoptosis}

Although $L K B 1$-null embryos displayed severe defects in developmental apoptosis, they showed a prominent cell death signal after the irradiation-induced DNA damage (Supplementary Figure 1b) as in the wild type (Supplementary Figure 1a), indicating that LKB1 is not required for the irradiationdependent cell death machinery that is fully dependent on p53 activity (Supplementary Figure 1c)..$^{41-43}$ Furthermore, ectopic apoptosis induced by p53 overexpression was not affected by LKB1 dosage reduction (Supplementary Figure 2e). Therefore, taken together with previous data showing that p53 is dispensable for LKB1-dependent apoptosis (Figure 4c-e), we concluded that LKB1 is dispensable for the p53-dependent cell death in Drosophila.

\section{LKB1 genetically interacts with the JNK pathway}

The remarkable contribution of LKB1 on apoptotic cell death prompted us to conduct a genetic modifier screening that was designed to search for additional components mediating the LKB1-induced apoptosis. By crossing $m s 1096>$ LKB1 ${ }^{\text {WT }}$ flies with $\sim 600$ independent EP/UAS lines, we obtained the $F_{1}$ progenies with wing-specific coexpression of a random gene and LKB1 (Figure 6a). These progenies were screened for modification of the ms1096 $>$ LKB1 ${ }^{\text {WT }}$ phenotype. Through 
this method, three independent UAS lines, UAS-Misshapen (Msn, Drosophila NIK), UAS-Hemipterous (Hep, Drosophila MKK7), and UAS-Basket (Bsk, Drosophila JNK), were identified as candidates. Although the sole expression of each candidate gene resulted in mild or undetectable phenotypic changes (Figure $6 \mathrm{~b}-\mathrm{e}$ ), simultaneous expression of the candidate genes with LKB1 strongly enhanced the $m s 1096>\mathrm{LKB} 1^{\mathrm{WT}}$ phenotype with a severe disruption in the structure and size of the wing blades (Figure $6 \mathrm{~g}-\mathrm{j}$ ). Interestingly, all of the candidates we identified - NIK, MKK7, and JNK - fell into a single signaling module, namely the JNK signaling pathway. Moreover, partial inactivation of the puckered (puc) gene, a JNK-specific dual-specificity phosphatase, dramatically enhanced the LKB1-induced small wing phenotype (Figure 6f,k), further confirming the connection between LKB1 and the JNK signaling pathway. ${ }^{49}$ Since the JNK

a

$$
\begin{gathered}
\frac{m s 1096>\mathrm{LKB} 1^{\mathrm{WT}}}{m s 1096>\mathrm{LKB}^{\mathrm{WT}}}+\frac{\mathrm{EP} / \mathrm{UAS} \text { element }}{\text { Autosome Balancer }} \\
\qquad \text { Non-balancer selection } \\
\underline{m s 1096>\mathrm{LKB} 1^{\mathrm{WT}}} ; \geq \underset{\mathrm{EP} / \mathrm{UAS} \text { element }}{\mathrm{Y}}
\end{gathered}
$$

b

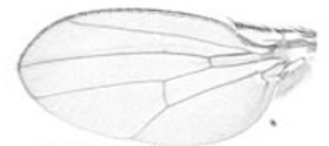

ms1096-Gal4

C

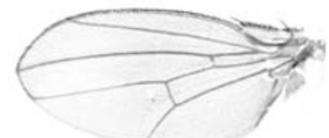

$m s 1096>$ Msn

d

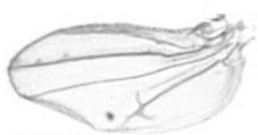

$m s 1096>\mathrm{Hep}$

e

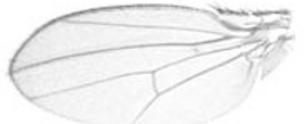

$m s 1096>$ Bsk $^{W T}$

f

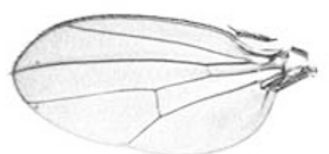

$m s 1096-\mathrm{Gal} 4$, puc $\mathrm{E}^{\mathrm{69} /+}$

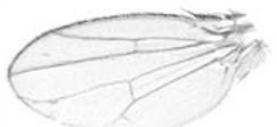

$m s 1096>$ LKB1 1 TT

h

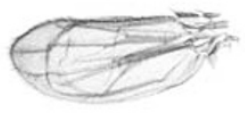

$m s 1096>M s n+L K B 1$ WT

i

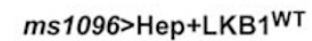

j

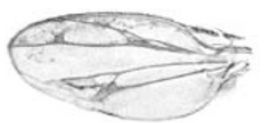

$m s 1096>\mathrm{Bsk}^{\mathrm{WT}}+\mathrm{LKB}{ }^{\mathrm{WT}}$

$\mathbf{k}$

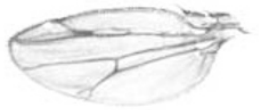

$m s 1096>\mathrm{LKB} 1^{\mathrm{WT}}, p u c^{\mathrm{E} 69 /+}$
Figure 6 The JNK pathway is involved in LKB1-induced organ size reduction. (a) Schematic representation of a strategy for screening genetic modifiers of LKB1. (b-k) Adult fly wings expressing transgenes under the control of the ms1096-Gal4 driver. Genotypes are ms1096-Gal4/Y (b), ms1096-Gal4/Y; UAS$\mathrm{Msn} /+$ (c), ms1096-Gal4/Y; UAS-Hep/ + (d), ms1096-Gal4/Y; UAS-Bsk ${ }^{\mathrm{WT}} /+$ (e), ms1096-Gal4/Y; puc E69; + (f), ms1096-Gal4 UAS-LKB1 ${ }^{\mathrm{WT}} / \mathrm{Y}$ (g), ms1096Gal4 UAS-LKB1 ${ }^{\text {WT }} / Y$; UAS-Msn/ + (h), ms1096-Gal4 UAS-LKB1 ${ }^{\mathrm{WT}} / \mathrm{Y}$; UAS$\mathrm{Hep} /+(\mathrm{i}), m_{1} 1096-\mathrm{Gal} 4 \mathrm{UAS}-\mathrm{LKB} 1^{\mathrm{WT}} / \mathrm{Y} ; \mathrm{UAS}^{-B s k}{ }^{\mathrm{WT}} /+$ (j), and $m s 1096-\mathrm{Gal} 4$ UAS-LKB1 ${ }^{\text {WT }} / Y ;$ puc $^{E 69} /+(\mathbf{k})$ signaling pathway regulates apoptosis both in the mammalian and Drosophila systems, we strongly suspected the JNK signaling pathway to be involved in the LKB1-induced apoptosis. $^{24-26}$

\section{LKB1 activates the JNK pathway}

To examine whether the JNK pathway is activated by LKB1, we first induced transient expression of Drosophila LKB1 by the hs-Gal4 driver (Figure 7a, fourth panel) in third instar larvae, and determined the biochemical status of JNK by immunoblot analyses. As shown in Figure 7a, the amount of activated JNK protein was significantly increased by the transgenic expression of LKB1 (Figure 7a, first panel), while the total amount of JNK protein remained unchanged (Figure 7a, second panel). Moreover, an electrophoretically retarded JNK band, corresponding to a highly phosphorylated and activated form of the protein, was observed in the same blot with longer exposure (Figure 7a, third panel). This biochemical evidence strongly implied JNK to be a physiological target of LKB1.

For further confirmation, we next attempted to test whether JNK activity is modulated by the tissue-specific expression of LKB1. For this purpose, we adopted the puc-LacZ reporter system to measure the activity of JNK signaling in vivo. ${ }^{26,29,50}$ puc is transcriptionally induced by JNK, forming a negative feedback loop of the JNK-dependent signaling pathway. ${ }^{49}$ As expected, eye-specific (Figure 7b,c) and wing-specific (Figure $7 d, e)$ expression of LKB1 induced a robust expression of the puc-LacZ reporter, indicating that JNK signaling is strongly activated by LKB1. Furthermore, immunohistochemistry using antiactive JNK antibody clearly confirmed that JNK activation occurred in the region of LKB1 overexpression (Figure $7 f, g$ ). All of these results consistently supported that LKB1 is an activator of JNK.

\section{JNK is indispensable for LKB1-induced apoptosis}

We next questioned whether the activation of JNK is absolutely required for the LKB1-dependent apoptosis. To fully inhibit JNK activity, we utilized a strong hep ${ }^{r 75}$ mutant allele, which was previously reported to have a minimal JNK activity in developing larval imaginal discs. ${ }^{29}$ Since Hep is the Drosophila homologue of mammalian MKK7, a well-known upstream kinase of JNK, we speculated that LKB1 would not activate JNK without Hep activity. As expected, in the hep ${ }^{r 75}$ mutant background, the gmr-Gal4 (Figure 8a, b) and the apGal4 (Figure 8c, d)-driven overexpression of LKB1 could not provoke JNK activation at all, implicating the requirement of Hep for the LKB1-dependent JNK activation. More importantly, in the hep $p^{r 75}$ mutant background, the LKB1-induced apoptosis in eye imaginal discs was also completely suppressed (Figure $8 \mathrm{e}, \mathrm{f}$ ). This clearly demonstrated that the JNK pathway is indispensable for the LKB1-induced apoptosis. Consistently, a partial downregulation of JNK activity by expressing kinase-dead JNK modestly suppressed the adult phenotype induced by the ap-Gal4-driven LKB1 overexpression (Figure $8 \mathrm{~g}, \mathrm{~h}$ ). Collectively, we concluded that LKB1 activates JNK via the Hep-dependent pathway, and this 


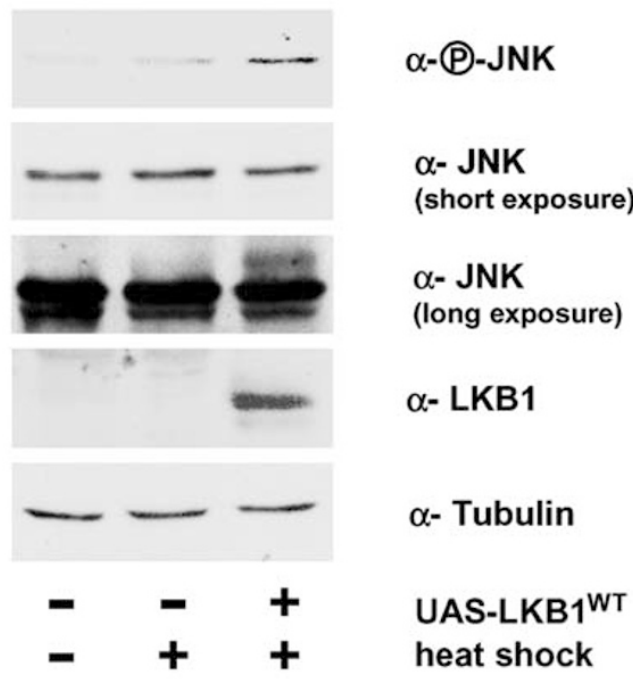

b

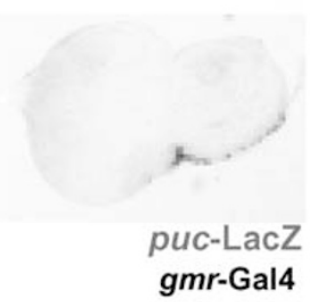

d
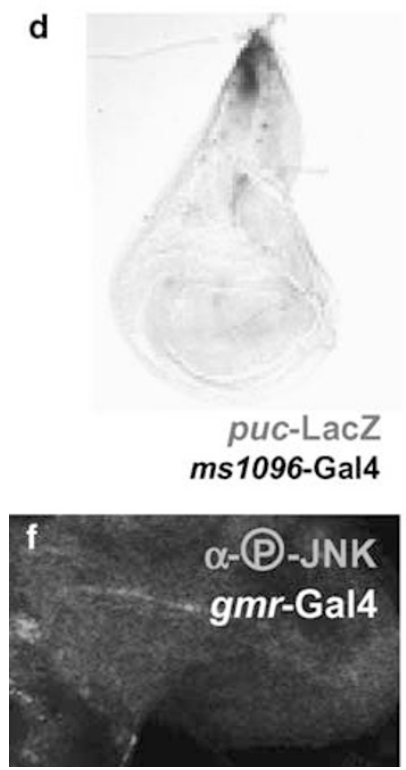

C

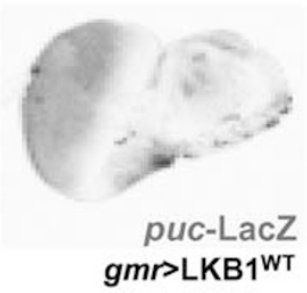

e

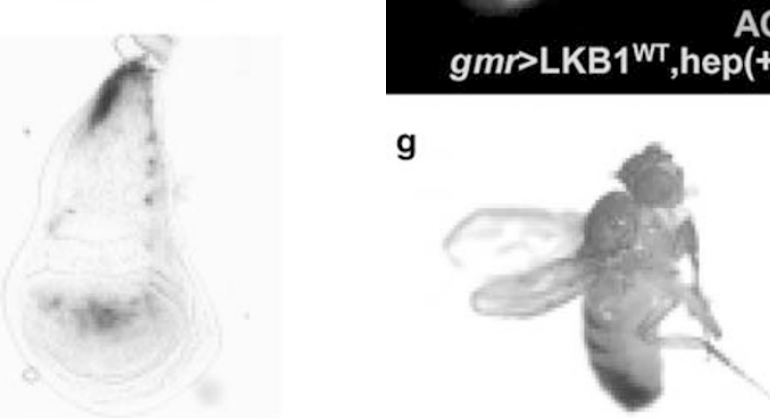

puc-LacZ $m s 1096>$ LKB1WT

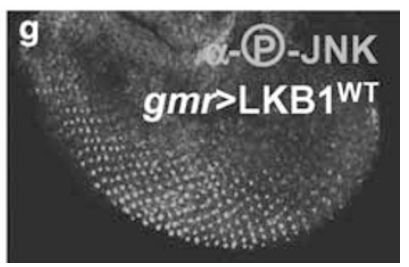

a

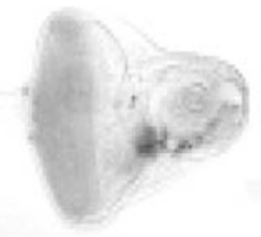

puc-LacZ
gmr $>$ LKB $1^{\text {WT }}$, hep(+)

C

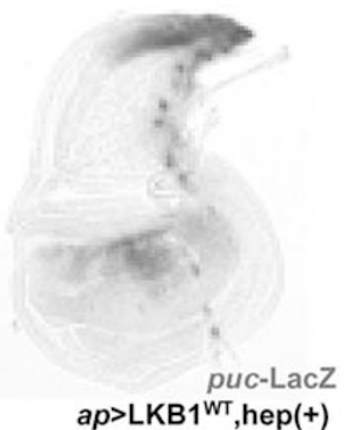

$a p>2 \times L K B 1$ wT $\mathrm{LKB}^{\mathrm{WT}} /+; \mathrm{UAS}-\mathrm{LKB} 1^{\mathrm{WT}} /+$ (h) b

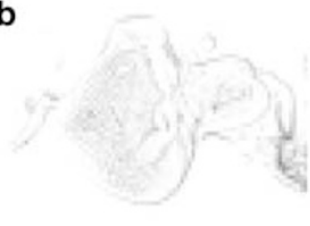
gmr>LKB1 ${ }^{\text {WT }}$,hep(-) d

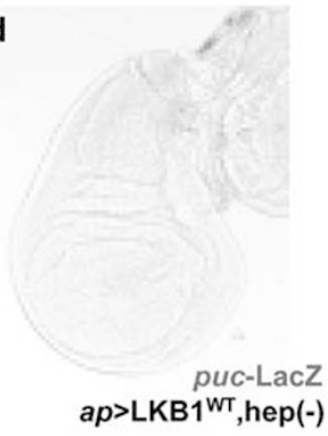

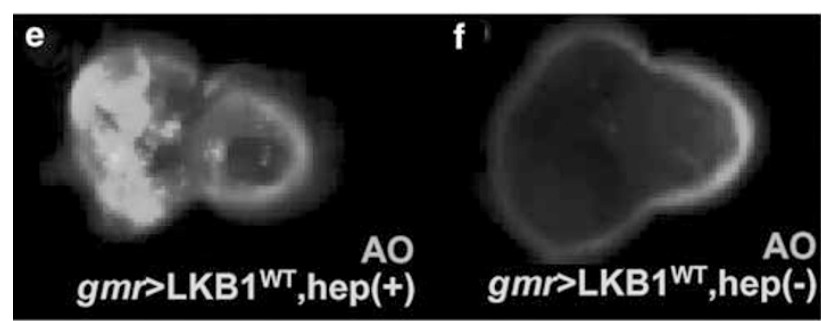

h

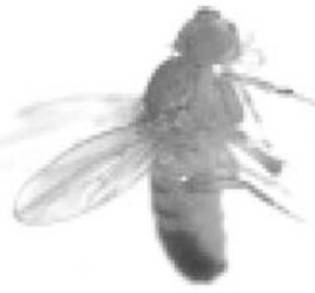

$a p>2 \times L K B 1^{W T}+B s k^{D N}$

Figure 8 The JNK pathway is required for LKB1-dependent apoptosis. (a-f) Hep is required for LKB1-dependent JNK activation and apoptosis. X-gal staining (a-d) and acridine orange (AO) staining (e, f) of gmr-Gal4 UAS-LKB $1^{\mathrm{WT}} /+$; pucLacZI + (a, e) and hep ${ }^{775} / \mathrm{Y} ;$ gmr-Gal4 UAS-LKB1 ${ }^{\mathrm{WT}} /+;$ puc-LacZ/ + (b, f) eye discs, and ap-Gal4 UAS-LKB1 ${ }^{\mathrm{WT}} /+$; puc-LacZ/ + (c) and hep ${ }^{r 75} / \mathrm{Y} ;$ ap-Gal4 UAS-LKB1 ${ }^{\mathrm{WT}} /+$; puc-LacZI + (d) wing discs. $(\mathbf{g}, \mathbf{h})$ Lateral views of the flies expressing transgenes under the control of $a p-G a l 4$. Genotypes are $+/ Y$; $a p$ Gal4 UAS-LKB1 ${ }^{\mathrm{WT}} /+$; UAS-LKB1 ${ }^{\mathrm{WT}} /+(\mathbf{g})$, UAS-Bsk ${ }^{\mathrm{DN}} / \mathrm{Y} ;$ ap-Gal4 UAS-

Figure 7 LKB1 activates the JNK pathway. (a) JNK phosphorylation induced by LKB1. Third instar larvae of $h s-G a l 4 /+$ (second lane) and hs-Gal4 UAS$\mathrm{LKB1}^{\mathrm{WT}} /$ + (third lane), which were heat-shock treated $(+)$ as described in Materials and Methods, as well as untreated $h s-G a l 4 /+$ (first lane) control (-) were subjected to immunoblot analyses with the indicated antibodies: antiphosphospecific JNK antibody for the first panel, anti-JNK antibody for the second and third panels, anti-LKB1 antibody for the fourth panel, and anti-tubulin antibody for the fifth panel. The third panel is a longer exposure of the second panel. (b-e) X-gal staining of gmr-Gal4/ + ; puc-LacZl + (b), and gmr-Gal4 UAS$\mathrm{LKB}^{\mathrm{WT}} /+$; puc-LacZ/ + (c) eye discs, and ms1096-Gal4/Y; puc-LacZI + (d) and ms1096-Gal4 UAS-LKB1 ${ }^{\text {WT }} / \mathrm{Y}$; puc-LacZI + (e) wing discs. (f, g) Antiphosphospecific JNK antibody staining of the eye discs from gmr-Gal4 (f) and gmrGal4 UAS-LKB1 ${ }^{\text {WT }}(\mathbf{g})$

activation is essential for the LKB1-dependent apoptosis in Drosophila.

\section{JNK is involved in LKB1-dependent neuronal apoptosis}

With JNK shown to be essential for the LKB1-dependent apoptosis, we next attempted to test the relationship between 
JNK and embryonic neuronal apoptosis, which is dependent on endogenous LKB1 activity (Figure 5). First, we examined whether JNK activity is associated with the embryonic apoptosis by costaining wild-type embryos with antiphosphospecific JNK antibody and TUNEL reaction. Interestingly, we observed many cells possessing both phospho-JNK and TUNEL signals, implicating the correlation between JNK activation and apoptotic cell death in embryonic neuronal cells (Figure 9a-c). Moreover, LKB1-null embryos did not show any prominent phospho-JNK signals compared to wild type (Figure 9d,e), showing that LKB1 is required for inducing JNK activation during embryogenesis. Furthermore, ectopic activation of JNK signaling by Hep overexpression restored embryonic apoptosis in LKB1-null embryos (Figure 9f, g), and completely rescued the big-brain phenotype of LKB1-null larvae (Figure 9h, i), while Hep overexpression itself did not induce any effects on wild-type brain size (Figure 9j). Therefore, we concluded that induction of the JNK-dependent apoptosis is one of the crucial functions of endogenous LKB1 during embryonic neuronal development in Drosophila.

\section{LKB1 is not essential for Eiger and TRAF1- dependent apoptosis}

As Eiger (Drosophila TNF ligand) and TRAF1 (Drosophila TNF receptor-associated factor) have been shown to induce JNK-dependent apoptosis, we questioned whether LKB1 is involved in the Eiger/TRAF1-dependent apoptotic pathway. ${ }^{50-52}$ Therefore, we tested genetic interaction between LKB1 and these genes. However, dosage reduction of LKB1 did not affect Eiger- or TRAF1-induced apoptosis at all
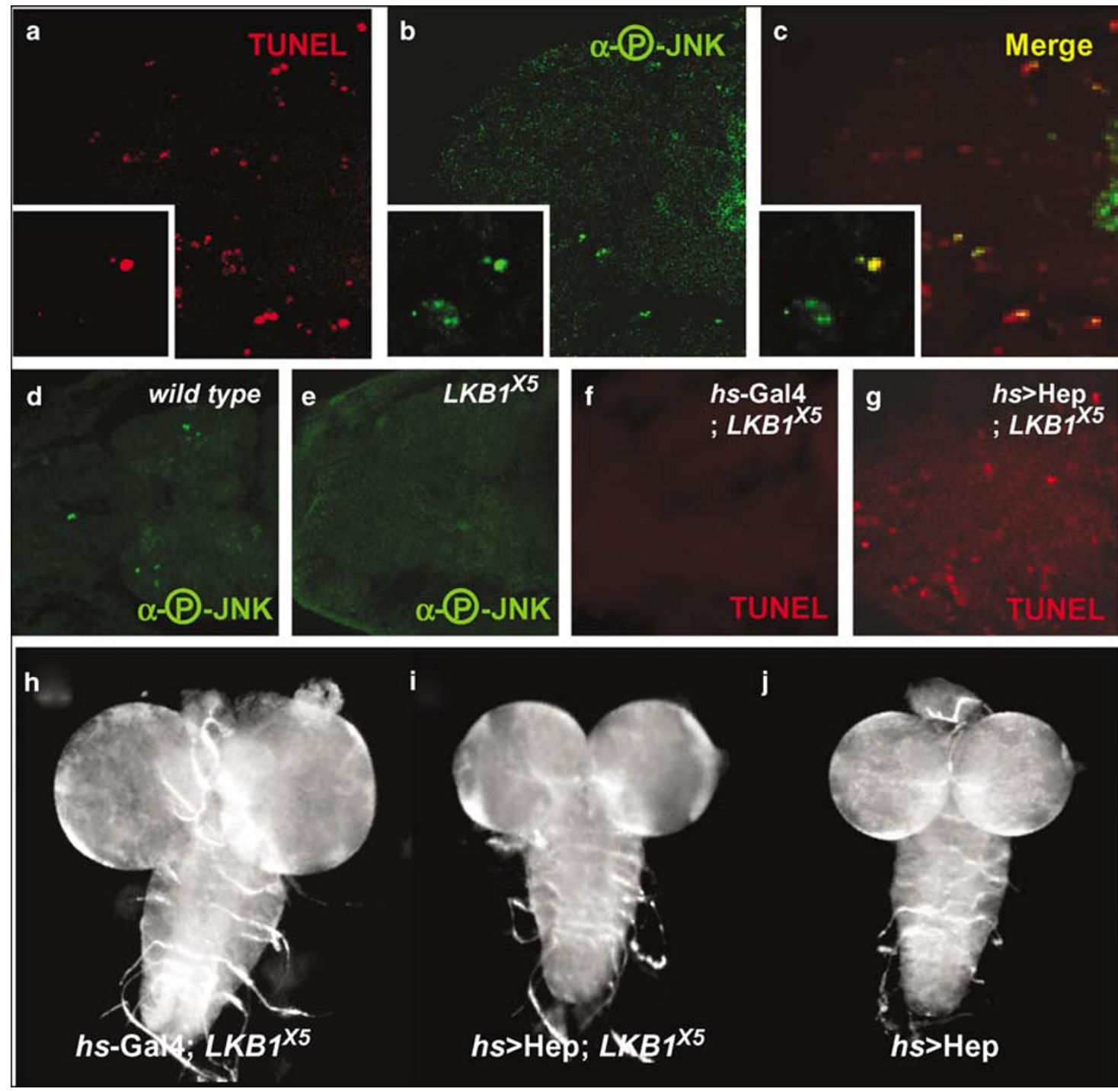

\section{i}
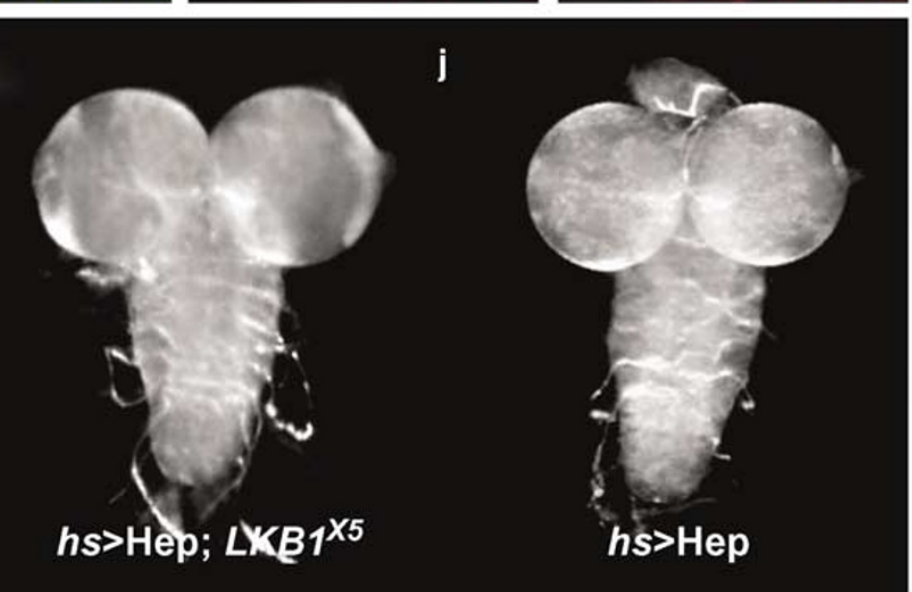

Figure 9 The JNK pathway is involved in the apoptosis caused by endogenous LKB1. (a-c) TUNEL (a, c; red spots) and antiphoshospecific JNK antibody staining (b, c; green spots) were simultaneously conducted in $w^{1118}$ embryonic head. Magnified views of representative region are presented as insets. (d, e) Antiphosphospecific JNK antibody staining of $w^{1118}(\mathbf{d})$ and $L K B 1^{X 5}(\mathbf{e})$ embryos. $(\mathbf{f}, \mathbf{g})$ Embryonic apoptosis of control $L K B 1^{X 5}$ (f) was rescued by transgenic expression of Hep $(\mathbf{g})$. Embryos were stained with TUNEL (red spots) to detect relative levels of apoptosis. (h-j) CNS dissections from third instar larvae of indicated genotypes. For transgenic expressions (f-j), heat-shock has been treated for $9-12 \mathrm{~h} \mathrm{AEL}$ at $37^{\circ} \mathrm{C}$. Quantification of brain phenotypes is presented in Supplementary Figure 3 as a bar graph 
(Supplementary Figure 2c, d and data not shown). Moreover, coexpression of these genes with LKB1 did not result in synergistic phenotype enhancement in contrast to other signaling components of the JNK pathway as shown in Figure 6 (data not shown). Furthermore, null mutants of eiger and TRAF1 displayed distinct phenotypes from $L K B 1$-null mutants. ${ }^{50,51}$ Therefore, we concluded there to be no direct involvement of LKB1 in the Eiger/TRAF1-dependent apoptotic pathway.

\section{LKB1 genetically interacts with JNK during thoracic morphogenesis}

Finally, since the JNK pathway is involved in the regulation of cytoskeletal structures, we determined whether LKB1 is involved in the JNK-dependent cell structure control. To achieve this, we examined whether the LKB1 knockdown causes thoracic development defects. When we reduced LKB1 expression in the thorax region by a complementary RNA hairpin corresponding to $L K B 1$ mRNA (LKBi), thoracic morphogenesis was significantly disrupted with bristle and scutellum formation defects (Supplementary Figure $4 a-d$ ). ${ }^{53}$ The same phenotypes were consistently observed with comparable penetrances (Supplementary Figure 4e) when dsRNAi was generated by other approaches such as usage of the hairpin construct with the inversed orientation (Inv) and of the SympUAST vector inducing symmetrical transcription to generate dsRNAi (Sym). ${ }^{53,54}$ Therefore, we concluded that LKB1 is involved in the thoracic morphogenetic processes.

To further relate these thoracic phenotypes of the LKB1 loss-of-function flies with the JNK pathway, we performed additional genetic analyses. Specifically, expression of Puc (Supplementary Figure 4f) or kinase-dead JNK (Supplementary Figure $4 \mathrm{~h}$ ) in the thorax by the ap-Gal4 driver led to a mild but significant thorax-open phenotype as previously described. $^{30,50}$ Intriguingly, RNAi-mediated LKB1 inhibition further enhanced these thorax phenotypes (Supplementary Figure $4 \mathrm{~g}, \mathrm{i})$, supporting that the endogenous functions of LKB1 and JNK are tightly related. Moreover, pnr-Gal4induced LKBi expression, which inhibited LKB1 activity at the dorsal-most region of the thorax, modestly suppressed the puc-LacZ reporter activity and ultimately resulted in a thoraxopen phenotype (Supplementary Figure 4j, k), implicating that LKB1 participates in the JNK-dependent thorax closure process.

\section{LKB1 controls JNK-dependent embryonic dorsal closure}

As LKB1 was involved in the JNK-dependent thoracic morphogenesis (Supplementary Figure 4), we tested whether downregulation of LKB1 activity could result in embryonic dorsal closure defects, which is a more typical outcome of reduced JNK activity in vivo. When dsRNAi corresponding to the coding region of $L K B 1$ mRNA (dsLKBi) was directly injected into wild-type Drosophila embryos, various dorsalopen phenotypes were induced in hatched (Supplementary Figure $5 \mathrm{~b}, \mathrm{c}$ ) or unhatched (Supplementary Figure $5 \mathrm{~d}, \mathrm{e}$ ) firstinstar larvae. These phenotypes were also observed in a small portion $(\sim 10 \%)$ of $L K B 1^{X 5}$ homozygotes (Supplementary Figure $5 \mathrm{f}, \mathrm{g}$ ), demonstrating the involvement of LKB1 in embryonic dorsal closure. Furthermore, transheterozygotic combinations between $L K B 1^{X 5}$ and basket (bsk ${ }^{1}$ and $b s k^{2}$ ) allele induced significant dorsal open phenotypes (Supplementary Figure $5 \mathrm{~h}, \mathrm{i}$ ) in unhatched first instar larvae. In addition, $L K B 1$-null mutant displayed a substantial reduction of $d p p$ transcription specifically in the dorsal-most region (Supplementary Figure 5j, k), which is dependent on the JNK activity and required for epithelial sheet movement. ${ }^{27}$ These results strongly implicated a functional interaction between LKB1 and JNK during embryonic development.

\section{Discussion}

Tumor suppressor LKB1 is a unique serine/threonine kinase with no close relatives in the mammalian genome. Likewise, only a single LKB1 orthologue exists in the Drosophila genome, implying well-conserved functional characteristics between the mammalian and Drosophila LKB1. ${ }^{22,55}$ Using the Drosophila model system, we discovered a novel functional connection between LKB1 and the JNK pathway: the JNK pathway is present downstream of the LKB1-dependent signaling pathway and controls apoptosis and organ size in response to LKB1 activities.

\section{Tumor suppressor LKB1 is a potent apoptosis instigator}

Previous studies on classical tumor suppressors in the Drosophila model system showed that hyperactivation of each tumor suppressor negatively regulates organ size by cell size reduction, cell cycle inhibition, or cell death promotion. ${ }^{39,42,56}$ This study presented that tumor suppressor LKB1 also negatively regulates organ size in Drosophila in a kinase activity-dependent manner (Figure 1). Recent reports on the TSC tumor suppressor suggested that LKB1 suppresses TOR activity via the TSC complex, ultimately resulting in inhibition of cell growth and proliferation. ${ }^{17,18}$ Likewise, we observed that TSC overexpression dramatically reduces cell size in Drosophila clonal overexpression analyses (Figure 2). However, unexpectedly, LKB1 overexpression did not induce any cell size reduction (Figure 2), in stark contrast to the case of TSC. Moreover, LKB1 overexpression in the clones of endoreplicating tissues altered neither cell size nor DNA content (data not shown), confirming that the tumor-suppressing activity of LKB1 is not related to the negative regulation of cell growth. Therefore, we concluded there to be no physiological connection between LKB1 and TSC in the context of cell growth control in Drosophila.

However, our histological analyses clearly demonstrated that the LKB1-overexpressing tissues suffer caspase-dependent programmed cell death, without apparent alteration in G1/S and G2/M cell cycle transition (Figure 3). The cell death induced by LKB1 overexpression displayed the most typical phenotypes of apoptosis, such as membrane integrity disruption, DNA fragmentation, and caspase activation (Figure 4). Furthermore, endogenous LKB1 was physiologically required for normal embryonic apoptosis, and also 
essential for the size control of the central nervous system (Figure 5). Consistent with our results, LKB1 was reported to be highly expressed in apoptotic cells of the small intestine in humans, and PJS polyps that lack the functional LKB1 protein possessed fewer apoptotic cells than in adjacent normal tissues. ${ }^{19}$ Collectively, these results strongly suggested that instigation of apoptosis is a critical function of tumor suppressor LKB1.

Surprisingly, in contradiction to previous research done with the mammalian system, the LKB1-induced apoptosis in Drosophila was a p53-independent event, as it was not blocked by the expression of a dominant-negative version of p53 (Figure 4). Moreover, apoptosis induced by DNA damage or p53 overexpression was also unaffected by downregulation of LKB1 activity (Supplementary Figure 1 and 2). Furthermore, diagnostic symptoms and major tumor types of PJS patients are highly distinct from those of $\mathrm{Li}-$ Fraumeni syndrome patients. ${ }^{11}$ Therefore, it is very likely that LKB1 and p53 are indirectly related as they both have caspase activation as a common downstream signaling event. ${ }^{41}$

\section{LKB1 functionally interacts with JNK}

Genetic screening using the Drosophila model system enabled us to discover the JNK pathway as a downstream effector of the LKB1-dependent signaling pathway. Through simple genetic screening, we analyzed more than 500 genes to interact with LKB1, which covers various signal transduction pathways including the Ras/ERK, JNK, PI3K, TOR, Wnt, TGF-beta, and NF- $\kappa$ B pathways (data not shown). Among them, some components of the JNK signaling pathway showed outstanding genetic interactions with LKB1, strongly enhancing the tissue-size reduction phenotype of LKB1 (Figure 6). This result implied the specific involvement of the JNK pathway in LKB1-dependent signal transduction, prompting us to conduct additional studies concerning the relationship between LKB1 and the JNK signaling pathway.

Our biochemical and histological analyses clearly demonstrated that JNK can be activated by LKB1 overexpression (Figure 7). As the kinase-dead mutant of LKB1 did not induce this JNK activation (Figure 1 and data not shown), this phenomenon seems to be a direct consequence of LKB1 phosphotransferase activity. Moreover, blockage of the JNK signaling pathway strongly suppressed the LKB1-induced apoptosis, as well as the tissue-size reduction (Figure 8). Furthermore, the activation of JNK signaling was shown to be involved in the physiological apoptosis induced by endogenous LKB1 (Figure 9). Therefore, we concluded that the JNK pathway acts as a downstream effector of LKB1 by mediating the LKB1-induced apoptosis. Accordingly, any signals upregulating the kinase activity of LKB1 would also activate the JNK pathway, ultimately leading to apoptosis in the cell. In fact, some microtubule-disrupting agents that induce the LKB1-dependent cell death also activate the JNK pathway to promote apoptosis. $^{19}$

Another interesting point of our research is that inhibition of LKB1 results in defective epithelial morphogenesis, which is associated with low JNK activity (Supplementary Figure 4 and 5). Several previous studies already demonstrated the requirement of LKB1 and JNK for epithelial integrity and polarity, both in the mammalian and Drosophila systems. ${ }^{21,22,27,57}$ Consistently, we observed that inhibition of LKB1 activity during development caused various morphogenesis defects including malformation of adult thoraxes and failure in embryonic dorsal closure. Furthermore, we also showed that LKB1 is required for maintaining adequate JNK activity during embryonic and larval development. Since loss of tissue integrity is a common feature of PJS polyps and cancer, the role of LKB1 in epithelial organization seems to be also important for mediating its tumor-suppressing activity.

Here, we demonstrated that the JNK pathway is involved in the LKB1-dependent apoptosis and epithelial morphogenesis in Drosophila. Since deregulation of both LKB1 and the JNK pathways is highly implicated in cancer development, the novel connection between LKB1 and the JNK signaling pathway provides a new direction for future studies in better understanding the complex functions of tumor suppressor LKB1.

\section{Materials and Methods}

\section{Fly stocks and genetics}

Full-length Drosophila LKB1 (GM01569, IMAGE), as well as its kinasedead form (K201I), was cloned into the pUAST vector prior to injection. dsRNAi transgenes were constructed against $519-1104$ base pairs of LKB1 coding sequence, as previously described. ${ }^{53,54}$ For direct RNAi microinjection, dsRNAi against 971-1479 base pairs of LKB1 was synthesized and microinjected into embryos as described. ${ }^{53}$ The Gal4 lines used in this study are $\mathrm{Ay}$-Gal4 ${ }^{58}$ ap-Gal4, ${ }^{38} \mathrm{gmr}$-Gal4, ${ }^{41} \mathrm{~ms} 1096$ Gal4 ${ }^{41} h s-G a l 4{ }^{50}$ and pnr-Gal4. ${ }^{30}$ Other stocks used in this study, UASHep, UAS-Bsk ${ }^{\text {WT }}$, and UAS-Bsk ${ }^{\mathrm{DN}}$ were gifts from Dr Mlodzik; puc ${ }^{\mathrm{E} 6}$, which is also called puc-LacZ, was a gift from Dr Adachi-Yamada; UASDIAP was a gift from Dr Hay; UAS-Puc was a gift from Dr Peifer; $L K B 1^{4 A 4-2}$ was a gift from Dr St Johnston; dpp-LacZ was a gift from $\mathrm{Dr}$ Kim; UAS-Eiger was obtained from Genexel Inc.; and $b s k^{1}, b s k^{2}$, hep ${ }^{r 75}$ Df(3L)H99, UAS-Reaper, gmr-Hid, Ay> GFP (Ay-Gal4 UAS-GFP), UASGFP, and UAS-Msn were obtained from the Bloomington Drosophila Stock Center. All flies were grown on standard cornmeal-yeast-agar medium at $25^{\circ} \mathrm{C}$.

$L K B 1^{E P-1}$ line was isolated from the GenExel's EP collection and subjected to imprecise excision as described. ${ }^{41}$ Among the $\sim 800$ excised allele, we found $L K B 1^{X 5}$ using PCR-based approaches. The molecular lesion of $L K B 1^{X 5}$ was determined by sequencing the genomic PCR product.

Clonal expression studies were performed using the $A y$-Gal4 system. ${ }^{58}$ In this system, clones in larval tissues were marked by GFP expression and clones in adult wing bristles were marked by a yellow color. Clone induction was conducted $80 \mathrm{~h}$ after egg-laying (AEL) and larval wing discs were analyzed $150 \mathrm{~h} \mathrm{AEL}$.

\section{Antibodies}

C-terminal protein (amino acids 468-567) of Drosophila LKB1 was used to generate anti-LKB1 mouse antisera. Antiphosphospecific JNK (Promega), anti-JNK (Santa-Cruz), antiactive human caspase-3 (CM1, Cell Signaling), antiactive Drice (a gift from Dr Hay), antiphosphospecific histone $\mathrm{H} 3$ (Upstate Laboratories), anti-tubulin E7, anti-LacZ JIE7, anti-Elav 9F8A9, and anti-BrdU G3G4 antibodies (DSHB, lowa) were used for immunoblot and histological analyses. 


\section{Immunoblot}

The third instar larvae of $h s-\mathrm{Gal} 4 /+$ (control) and $h s>\mathrm{LKB} 1^{\mathrm{WT}} /+$ were heat-shocked at $37^{\circ} \mathrm{C}$ for $30 \mathrm{~min}$ in a water bath and allowed to recover at $25^{\circ} \mathrm{C}$ for $2 \mathrm{~h}$ before processing. The larvae were homogenized as previously described. ${ }^{38}$ Proteins in the denatured supernatant were immunoblotted with the indicated antibodies after separation in sodium dodecyl sulfate-polyacrylamide gel.

\section{Histology}

Adult wing blades were mounted in 50\% Canadian balsam (Sigma) in methyl salicylate (Fischer). GFP visualization, ${ }^{50} \mathrm{BrdU}$ incorporation assay, ${ }^{59}$ AO staining, ${ }^{41}$ TUNEL in situ, ${ }^{50}$ and $X$-Gal staining ${ }^{50}$ were performed as described. For the selection of $L K B 1^{X 5}$ homozygous embryos, we utilized TM3-LacZ and TM3-GFP balancers. ${ }^{38}$ For the cuticle preparations, dechorionated embryos or larvae were immersed in a solution containing acetic acid and glycerol at a $3: 1$ ratio and incubated $3 \mathrm{~h}$ at $65^{\circ} \mathrm{C}$. Embryos and larvae were then mounted in Hoyer's medium and incubated $24 \mathrm{~h}$ at $65^{\circ} \mathrm{C}$.

\section{References}

1. Hemminki A, Markie D, Tomlinson I, Avizienyte E, Roth S, Loukola A, Bignell G, Warren W, Aminoff M, Hoglund P, Jarvinen H, Kristo P, Pelin K, Ridanpaa M, Salovaara R, Toro T, Bodmer W, Olschwang S, Olsen AS, Stratton MR, de la Chapelle A and Aaltonen LA (1998) A serine/threonine kinase gene defective in Peutz-Jeghers syndrome. Nature 391: 184-187

2. Jenne DE, Reimann H, Nezu J, Friedel W, Loff S, Jeschke R, Muller O, Back W and Zimmer M (1998) Peutz-Jeghers syndrome is caused by mutations in a novel serine threonine kinase. Nat. Genet. 18: 38-43

3. Giardiello FM, Welsh SB, Hamilton SR, Offerhaus GJ, Gittelsohn AM, Booker SV, Krush AJ, Yardley JH and Luk GD (1987) Increased risk of cancer in the Peutz-Jeghers syndrome. N. Engl. J. Med. 316: 1511-1514

4. Spigelman AD, Murday V and Phillips RK (1989) Cancer and the PeutzJeghers syndrome. Gut 30: 1588-1590

5. Boardman LA, Thibodeau SN, Schaid DJ, Lindor NM, McDonnell SK, Burgart LJ, Ahlquist DA, Podratz KC, Pittelkow M and Hartmann LC (1998) Increased risk for cancer in patients with the Peutz-Jeghers syndrome. Ann. Intern. Med. 128: 896-899

6. Entius MM, Keller JJ, Westerman AM, van Rees BP, van Velthuysen ML, de Goeij AF, Wilson JH, Giardiello FM and Offerhaus GJ (2001) Molecular genetic alterations in hamartomatous polyps and carcinomas of patients with PeutzJeghers syndrome. J. Clin. Pathol. 54: 126-131

7. Gruber SB, Entius MM, Petersen GM, Laken SJ, Longo PA, Boyer R, Levin AM, Mujumdar UJ, Trent JM, Kinzler KW, Vogelstein B, Hamilton SR, Polymeropoulos MH, Offerhaus GJ and Giardiello FM (1998) Pathogenesis of adenocarcinoma in Peutz-Jeghers syndrome. Cancer Res. 58: 5267-5270

8. Sahin F, Maitra A, Argani P, Sato N, Maehara N, Montgomery E, Goggins M, Hruban RH and Su GH (2003) Loss of Stk11/Lkb1 expression in pancreatic and biliary neoplasms. Mod. Pathol. 16: 686-691

9. Shen Z, Wen XF, Lan F, Shen ZZ and Shao ZM (2002) The tumor suppressor gene LKB1 is associated with prognosis in human breast carcinoma. Clin. Cancer Res. 8: 2085-2090

10. Sanchez-Cespedes M, Parrella P, Esteller M, Nomoto S, Trink B, Engles JM, Westra WH, Herman JG and Sidransky D (2002) Inactivation of LKB1/STK11 is a common event in adenocarcinomas of the lung. Cancer Res. 62: 3659-3662

11. Yoo LI, Chung DC and Yuan J (2002) LKB1 - a master tumour suppressor of the small intestine and beyond. Nat. Rev. Cancer 2: 529-535

12. Boudeau J, Kieloch A, Alessi DR, Stella A, Guanti G and Resta N (2003) Functional analysis of LKB1/STK11 mutants and two aberrant isoforms found in Peutz-Jeghers Syndrome patients. Hum. Mutat. 21: 172

13. Boudeau J, Sapkota G and Alessi DR (2003) LKB1, a protein kinase regulating cell proliferation and polarity. FEBS Lett. 546: 159-165
14. Tiainen M, Ylikorkala A and Makela TP (1999) Growth suppression by Lkb1 is mediated by a G(1) cell cycle arrest. Proc. Natl. Acad. Sci. USA 96: 9248-9251

15. Marignani PA, Kanai $F$ and Carpenter CL (2001) LKB1 associates with Brg1 and is necessary for Brg1-induced growth arrest. J. Biol. Chem. 276: 3241532418

16. Tiainen M, Vaahtomeri K, Ylikorkala A and Makela TP (2002) Growth arrest by the LKB1 tumor suppressor: induction of p21(WAF1/CIP1). Hum. Mol. Genet. 11: $1497-1504$

17. Shaw RJ, Bardeesy N, Manning BD, Lopez L, Kosmatka M, DePinho RA and Cantley LC (2004) The LKB1 tumor suppressor negatively regulates mTOR signaling. Cancer Cell 6: 91-99

18. Corradetti MN, Inoki K, Bardeesy N, DePinho RA and Guan KL (2004) Regulation of the TSC pathway by LKB1: evidence of a molecular link between tuberous sclerosis complex and Peutz-Jeghers syndrome. Genes Dev. 18: 1533-1538

19. Karuman P, Gozani O, Odze RD, Zhou XC, Zhu H, Shaw R, Brien TP, Bozzuto CD, Ooi D, Cantley LC and Yuan J (2001) The Peutz-Jegher gene product LKB1 is a mediator of p53-dependent cell death. Mol. Cell. 7: 1307-1319

20. Sapkota GP, Kieloch A, Lizcano JM, Lain S, Arthur JS, Williams MR, Morrice N, Deak $M$ and Alessi DR (2001) Phosphorylation of the protein kinase mutated in Peutz-Jeghers cancer syndrome, LKB1/STK11, at Ser431 by p90(RSK) and cAMP-dependent protein kinase, but not its farnesylation at Cys(433), is essential for LKB1 to suppress cell growth. J. Biol. Chem. 276: 19469-19482

21. Baas AF, Kuipers J, van der Wel NN, Batlle E, Koerten HK, Peters PJ and Clevers HC (2004) Complete polarization of single intestinal epithelial cells upon activation of LKB1 by STRAD. Cell 116: 457-466

22. Martin SG and St Johnston D (2003) A role for Drosophila LKB1 in anteriorposterior axis formation and epithelial polarity. Nature 421: 379-384

23. Davis RJ (2000) Signal transduction by the JNK group of MAP kinases. Cell 103: 239-252

24. Tournier C, Hess P, Yang DD, Xu J, Turner TK, Nimnual A, Bar-Sagi D, Jones SN, Flavell RA and Davis RJ (2000) Requirement of JNK for stress-induced activation of the cytochrome $c$-mediated death pathway. Science 288: 870-874

25. Kuan CY, Yang DD, Samanta Roy DR, Davis RJ, Rakic $P$ and Flavell RA (1999) The Jnk1 and Jnk2 protein kinases are required for regional specific apoptosis during early brain development. Neuron 22: 667-676

26. Adachi-Yamada T, Fujimura-Kamada K, Nishida Y and Matsumoto K (1999) Distortion of proximodistal information causes JNK-dependent apoptosis in Drosophila wing. Nature 400: 166-169

27. Xia $Y$ and Karin M (2004) The control of cell motility and epithelial morphogenesis by Jun kinases. Trends Cell Biol. 14: 94-101

28. Riesgo-Escovar JR, Jenni M, Fritz A and Hafen E (1996) The Drosophila Jun$\mathrm{N}$-terminal kinase is required for cell morphogenesis but not for DJundependent cell fate specification in the eye. Genes Dev. 10: 2759-2768

29. Agnes F, Suzanne M and Noselli S (1999) The Drosophila JNK pathway controls the morphogenesis of imaginal discs during metamorphosis. Development 126: 5453-5462

30. Zeitlinger $\mathrm{J}$ and Bohmann D (1999) Thorax closure in Drosophila: involvement of Fos and the JNK pathway. Development 126: 3947-3956

31. Boutros M, Paricio N, Strutt DI and Mlodzik M (1998) Dishevelled activates JNK and discriminates between JNK pathways in planar polarity and wingless signaling. Cell 94: 109-118

32. Weston CR, Wong A, Hall JP, Goad ME, Flavell RA and Davis RJ (2003) JNK initiates a cytokine cascade that causes Pax2 expression and closure of the optic fissure. Genes Dev. 17: 1271-1280

33. Kennedy NJ and Davis RJ (2003) Role of JNK in tumor development. Cell Cycle 2: 199-201

34. Kennedy NJ, Sluss HK, Jones SN, Bar-Sagi D, Flavell RA and Davis RJ (2003) Suppression of Ras-stimulated transformation by the JNK signal transduction pathway. Genes Dev. 17: 629-637

35. Yoshida S, Fukino K, Harada H, Nagai H, Imoto I, Inazawa J, Takahashi H, Teramoto A and Emi M (2001) The c-Jun $\mathrm{NH}_{2}$-terminal kinase3 (JNK3) gene: genomic structure, chromosomal assignment, and loss of expression in brain tumors. J. Hum. Genet. 46: 182-187

36. Teng DH, Perry Jr WL, Hogan JK, Baumgard M, Bell R, Berry S, Davis T, Frank D, Frye C, Hattier T, Hu R, Jammulapati S, Janecki T, Leavitt A, Mitchell JT, Pero R, Sexton D, Schroeder M, Su PH, Swedlund B, Kyriakis JM, Avruch J, Bartel P, Wong AK and Tavtigian SV (1997) Human mitogen-activated protein kinase kinase 4 as a candidate tumor suppressor. Cancer Res. 57: 4177-4182 
37. Yoshida BA, Dubauskas Z, Chekmareva MA, Christiano TR, Stadler WM and Rinker-Schaeffer CW (1999) Mitogen-activated protein kinase kinase 4/stressactivated protein/Erk kinase 1 (MKK4/SEK1), a prostate cancer metastasis suppressor gene encoded by human chromosome 17. Cancer Res. 59: 54835487

38. Cho KS, Lee JH, Kim S, Kim D, Koh H, Lee J, Kim C, Kim J and Chung J (2001) Drosophila phosphoinositide-dependent kinase-1 regulates apoptosis and growth via the phosphoinositide 3-kinase-dependent signaling pathway. Proc. Natl. Acad. Sci. USA 98: 6144-6149

39. Tapon N, Ito N, Dickson BJ, Treisman JE and Hariharan IK (2001) The Drosophila tuberous sclerosis complex gene homologs restrict cell growth and cell proliferation. Cell 105: 345-355

40. Potter CJ, Huang H and Xu T (2001) Drosophila Tsc1 functions with Tsc2 to antagonize insulin signaling in regulating cell growth, cell proliferation, and organ size. Cell 105: 357-368

41. Lee JH, Lee E, Park J, Kim E, Kim J and Chung J (2003) In vivo p53 function is indispensable for DNA damage-induced apoptotic signaling in Drosophila. FEBS Lett. 550: 5-10

42. Brodsky MH, Nordstrom W, Tsang G, Kwan E, Rubin GM and Abrams JM (2000) Drosophila p53 binds a damage response element at the reaper locus. Cell 101: 103-113

43. Ollmann M, Young LM, Di Como CJ, Karim F, Belvin M, Robertson S, Whittaker K, Demsky M, Fisher WW, Buchman A, Duyk G, Friedman L, Prives C and Kopezynski C (2000) Drosophila p53 is a structural and functional homolog of the tumor suppressor p53. Cell 101: 91-101

44. Hawkins CJ, Wang SL and Hay BA (1999) A cloning method to identify caspases and their regulators in yeast: identification of Drosophila IAP1 as an inhibitor of the Drosophila caspase DCP-1. Proc. Natl. Acad. Sci. USA 96: 2885-2890

45. Abrams JM, White K, Fessler LI and Steller H (1993) Programmed cell death during Drosophila embryogenesis. Development 117: 29-43

46. Kanuka H, Sawamoto K, Naohiro I, Matsuno K, Okano H and Miura M (1999) Control of the cell death pathway by Dapaf-1, a Drosophila Apaf-1/CED-4related capase activator. Mol. Cell 4: 757-769

47. Rodriguez A, Oliver H, Zou H, Chen P, Wang X and Abrams JM (1999) Dark is a Drosophila homologue of Apaf-1/CED-4 and functions in an evolutionarily conserved death pathway. Nat. Cell Biol. 1: 272-279
48. White $\mathrm{K}$, Grether ME, Abrams JM, Young L, Farrell $\mathrm{K}$ and Steller $\mathrm{H}$ (1994) Genetic control of programmed cell death in Drosophila. Science 264: 677-683

49. Martin-Blanco E, Gampel A, Ring J, Virdee K, Kirov N, Tolkovsky AM and Martinez-Arias A (1998) puckered encodes a phosphatase that mediates a feedback loop regulating JNK activity during dorsal closure in Drosophila. Genes Dev. 12: 557-570

50. Cha GH, Cho KS, Lee JH, Kim M, Kim E, Park J, Lee SB and Chung J (2003) Discrete functions of TRAF1 and TRAF2 in Drosophila melanogaster mediated by c-Jun N-terminal kinase and NF-kappaB-dependent signaling pathways. Mol. Cell. Biol. 23: 7982-7991

51. Igaki $\mathrm{T}$, Kanda $\mathrm{H}$, Yamamoto-Goto $\mathrm{Y}$, Kanuka $\mathrm{H}$, Kuranaga $\mathrm{E}$, Aigaki $\mathrm{T}$ and Miura M (2002) Eiger, a TNF superfamily ligand that triggers the Drosophila JNK pathway. EMBO J. 21: 3009-3018

52. Kuranaga E, Kanuka H, Igaki T, Sawamoto K, Ichijo H, Okano $H$ and Miura M (2002) Reaper-mediated inhibition of DIAP1-induced DTRAF1 degradation results in activation of JNK in Drosophila. Nat. Cell Biol. 4: 705-710

53. Kennerdell JR and Carthew RW (2000) Heritable gene silencing in Drosophila using double-stranded RNA. Nat. Biotechnol. 18: 896-898

54. Giordano E, Rendina R, Peluso I and Furia M (2002) RNAi triggered by symmetrically transcribed transgenes in Drosophila melanogaster. Genetics 160: 637-648

55. Fortini ME, Skupski MP, Boguski MS and Hariharan IK (2000) A survey of human disease gene counterparts in the Drosophila genome. J. Cell. Biol. 150: F23-F30

56. Du W, Vidal M, Xie JE and Dyson N (1996) RBF, a novel RB-related gene that regulates E2F activity and interacts with cyclin E in Drosophila. Genes Dev. 10: 1206-1218

57. Shen J and Dahmann C (2005) Extrusion of cells with inappropriate Dpp signaling from Drosophila wing disc epithelia. Science 307: 1789-1790

58. Ito K, Awano W, Suzuki K, Hiromi Y and Yamamoto D (1997) The Drosophila mushroom body is a quadruple structure of clonal units each of which contains a virtually identical set of neurones and glial cells. Development 124: 761-771

59. Kim M, Cha GH, Kim S, Lee JH, Park J, Koh H, Choi KY and Chung J (2004) MKP-3 has essential roles as a negative regulator of the Ras/mitogen-activated protein kinase pathway during Drosophila development. Mol. Cell. Biol. 24: $573-583$

Supplementary Information accompanies the paper on Cell Death and Differentiation website (http://www.nature.com/cdd) 